\title{
THE
}

\section{The Effect of Light Intensity on Prey Detection Behavior in Two Lake Malawi Cichlids, Aulonocara stuartgranti and Tramitichromis}

sp.

Margot A.B. Schwalbe

Jacqueline F. Webb

University of Rhode Island, jacqueline_webb@uri.edu

Follow this and additional works at: https://digitalcommons.uri.edu/bio_facpubs

The University of Rhode Island Faculty have made this article openly available. Please let us know how Open Access to this research benefits you.

This is a pre-publication author manuscript of the final, published article.

Terms of Use

This article is made available under the terms and conditions applicable towards Open Access Policy Articles, as set forth in our Terms of Use.

\section{Citation/Publisher Attribution}

Schwalbe MA, Webb JF. (2015). "The Effect of Light Intensity on Prey Detection Behavior in Two Lake Malawi Cichlids, Aulonocara stuartgranti and Tramitichromis sp." Journal of Comparative Physiology A: Neuroethology, Sensory, Neural, and Behavioral Physiology. Available at: http://link.springer.com/article/ 10.1007/s00359-015-0982-y\# 

The effect of light intensity on prey detection behavior in two Lake Malawi cichlids, Aulonocara stuartgranti and Tramitichromis sp.

4

5

6

7

8

Margot A. B. Schwalbe ${ }^{1}$ and Jacqueline F. Webb ${ }^{1}$

9

$10{ }^{1}$ Department of Biological Sciences, University of Rhode Island, 120 Flagg Road, Kingston, RI 11 02881, USA

12

13

14 Author for Correspondence: Margot A. B. Schwalbe, Department of Biology, Tufts University, 15200 Boston Ave, Ste. 4700, Medford, MA USA; margot.schwalbe@tufts.edu,

16 margot.schwalbe@gmail.com, telephone: (617) 627-0558, fax: (617) 627-0309

17

18

19

Tables: 5

20

Figures: 7 ( 2 color)

21

22

23 


\section{Abstract}

Two Lake Malawi sand-dwelling cichlids (Aulonocara stuartgranti, Tramitichromis sp.) that

27 have different lateral line phenotypes, but feed on benthic invertebrates, have been shown to use

28

29

\section{Abbreviations}

45

46

\section{Keywords}

AICC

GLMM lateral line and/or visual cues to detect prey under light versus dark conditions. The current study examined how ecologically relevant variation in light intensity (0-800 lux) influences detection of prey (mobile, immobile) in each species by analyzing six well-defined behavioral parameters. Both species fed at light intensities $\geq 1$ lux; prey type and/or time of day (but not light intensity) predicted all four parameters analyzed with generalized linear mixed models in A. stuartgranti, whereas the interaction of light intensity and time of day predicted three of these parameters in Tramitichromis sp. Data for all six parameters suggest that the critical light intensity is 1-12 lux for both species, the integration of visual and lateral line input explains differences in the detection of mobile and immobile prey and the behavioral changes that occur at the transition from 1 to 0 lux in A. stuartgranti, and that Tramitichromis sp. likely uses binocular vision to locate prey. The sensory biology of species that exploit similar food resources will have important implications for the trophic ecology of African cichlid fishes.

Vision, lateral line, detection distance, prey detection, sensory ecology

Akaike information criterion

Generalized linear mixed model 
$47 \quad$ Lx Lux

48 PAR Photosynthetically active radiation

49 SL Standard length

50 TL Total length

52 Introduction

54 Light in aquatic habitats varies in quality and quantity over time and space (Kirk 2011) and 55 influences the ability of visual predators to detect and capture mobile prey (Vinyard and O’Brien 56 1976; Confer et al. 1978; Lythgoe 1979; Ryer and Olla 1999; Vogel and Beauchamp 1999;

57 Rickel and Genin 2005). Fishes occupying similar habitats may demonstrate variation in 58 visually-mediated prey detection abilities, such as visual thresholds and absorption spectra of 59 visual pigments, which may provide a competitive advantage under particular light conditions 60 (Vogel and Beauchamp 1999; Hofmann et al. 2009). Many fishes are also able to detect prey at 61 low light intensities (e.g., dawn, dusk, at depth, or with increased turbidity), but with reduced 62 capabilities compared to that at higher light intensities. The distance at which free swimming 63 prey are detected dramatically decreases below a certain light intensity ("critical light intensity," 64 Confer et al. 1978) in salmonids (Dunbrack and Dill 1984; Henderson and Northcote 1985) and 65 some freshwater percomorphs (bluegill, Lepomis macrochirus, Vinyard and O’Brien 1976; 66 largemouth bass, Micropterus salmoides, Howick and O’Brien 1983; yellow perch, Perca 67 flavescans, Richmond et al. 2004).

Given the importance of multimodal sensory integration in the formulation of behavior, 69 the contributions of the non-visual sensory systems to prey detection (e.g., mechanosensory 
lateral line, auditory, olfactory, gustatory, somatosensory/tactile, and in some cases, the electrosensory system; reviewed in Montgomery et al. 2014) must also be considered.

72 Morphological and/or physiological specializations of non-visual sensory systems, including the 73 olfactory system (Parzefall 1993; Montgomery et al. 1999), gustatory system (Atema 1971) and

74 the lateral line system (Janssen 1997; Schwalbe et al. 2012, reviewed in Webb 2014), have been 75 used to predict how these senses provide alternatives to vision for prey detection in light-limited 76 environments. Futhermore, the integration of different combinations of sensory inputs may 77 explain variation in behavior under different environmental conditions (Partridge and Pitcher 1980; Moller 2002; Montgomery et al. 2003; Gardiner and Motta 2012). Several species of fishes

79 have been shown to modulate feeding strategies using a combination of visual and non-visual 80 cues that allow them to feed under a range of light conditions, including darkness (Townsend and 81 Risebrow 1982; Batty et al. 1986; Diehl 1988; Schwalbe et al. 2012).

82 The mechanosensory lateral line system is known to play important roles in prey 83 detection, as well as in predator avoidance, communication, and navigation around obstacles 84 (Webb et al. 2008; Montgomery et al. 2014). The system demonstrates a great deal of variation, 85 which is defined by the morphology of the cranial and trunk lateral line canals and neuromast 86 receptor organs within them, and the distribution of superficial neuromasts on the skin of the 87 head, trunk and tail (reviewed in Webb 2014). Widened lateral line canals, one of five cranial 88 lateral line canal phenotypes found among bony fishes, has evolved convergently in $\sim 12$ teleost 89 families (including deep sea taxa) and appears to be an adaptation for enhanced sensitivity to 90 water flows and prey detection (Denton and Gray 1988, 1989; Montgomery and Coombs 1992;

91 discussed in Schwalbe et al. 2012; reviewed in Webb 2014). 
The speciose cichlid fishes of the African Rift Lakes are typically described as visual feeders (Fryer and Iles 1972) and most genera have narrow cranial lateral line canals, but all members of a few genera (e.g., Alticorpus, Aulonocara, Aulonocranus, Trematocara,

95 Trematocranus, Konings 2007) have widened lateral line canals suggesting the capacity for lateral line mediated prey detection (Konings 1990). Two genera of non-mbuna, haplochromine cichlids in Lake Malawi, Aulonocara (widened canals) and Tramitichromis (narrow canals; Fig. 1), provide an interesting taxon pair for comparison of prey detection strategies since both feed on benthic invertebrates in the sand, and thus appear to be ecologically similar. Schwalbe et al. (2012) and Schwalbe and Webb (2014) analyzed the behavioral responses of Aulonocara stuartgranti and Tramitichromis sp. to tethered live and dead prey (=adult brine shrimp, Artemia sp.), in experiments carried out under light and dark conditions in which the lateral line system was experimentally inactivated. These studies demonstrated that $A$. stuartgranti uses a combination of inputs to its visual and lateral line systems to detect prey in the light, but depends on its lateral line system to detect prey in the dark. Furthermore, these studies showed that deactivation of the lateral line system of $A$. stuartgranti significantly affected prey detection behavior and revealed that other senses (olfaction, gustation, and somatosensory/tactile) were insufficient to initiate prey detection behavior in the dark. In contrast, Tramitichromis sp. did not feed in the dark, and the inactivation of the lateral line system had little effect on prey detection behavior in the presence of light, demonstrating that it is a visual predator. Aulonocara and Tramitichromis species appear to share a food resource (benthic invertebrates in sandy substrates), but occupy different depth ranges (Aulonocara species at depths of 5-120 m and Tramitichromis species at depths of $<15 \mathrm{~m}$; Fryer and Iles 1972; Konings 1990, 2007) and use different strategies to detect and capture benthic invertebrate prey in the 
115 field. Species of Aulonocara swim just above the substrate to sense hydrodynamic flows

116 generated by benthic invertebrates in or on the substrate in the field (Konings 2007). In contrast,

117 species of Tramitichromis typically capture invertebrate prey by plunging into the substrate,

118 filling their mouth with sand, and sifting out prey with their gill rakers in the field (= "sand

119 sifting," Fryer, 1959). This sand sifting behavior appears to be synonymous with the

120 “winnowing” behaviors observed in some surfperches (Laur and Ebeling 1983) and vision likely

121 contributes to the ability to locate patches of high quality food resources where "winnowing"

122 takes place (Holbrook and Schmitt 1984; Schmitt and Holbrook 1984).

123 This study uses the same methods used in prior studies (Schwalbe et al. 2012; Schwalbe

124 and Webb 2014) to test the hypothesis that variation in light intensity (0-800 1x) will have

125 different effects on the detection of live (mobile) and dead (immobile) benthic invertebrate prey

126 in A. stuartgranti and Tramitichromis sp.

127

128 Materials and methods

129

130 Study species

131

132 Adult Aulonocara stuartgranti and Tramitichromis sp. (unidentifiable to species level, J.

133 Stauffer, pers. commun.), is referred to as Tramitichromis throughout. These fish were reared in

134 the laboratory from breeding stock originally acquired from commercial suppliers $(A$.

135 stuartgranti: Bluegrass Aquatics, Louisville, KY, USA; Tramitichromis: Old World Exotic Fish,

136 Inc., Homestead, FL, USA and Life Fish Direct, Draper, UT, USA). They were housed in small

137 groups by species in $190 \mathrm{~L}$ aquaria at $26 \pm 1^{\circ} \mathrm{C}$ and $1.0 \pm 0.2$ p.p.t. salinity (using Cichlid Lake Salt, 
138 Seachem Laboratories, Inc., Madison, GA, USA) with standard white fluorescent light on a

139 12h:12h diurnal cycle and, equipped with appropriate mechanical and biological filtration. Fish

140 were fed daily with cichlid pellets (New Life Spectrum Cichlid Formula; New Life International,

141 Inc., Homestead, FL) and supplemented with live adult brine shrimp. Individual fish were not

142 used in feeding experiments if breeding behavior was observed. Animal care and all

143 experimental procedures followed an approved IACUC protocol.

145 Light environment in the experimental tank

146

147 Light in the experimental tank was provided by two fluorescent light fixtures (Lithonia Lighting,

148 Model GRW 214 CSW CO M4, Conyers, GA, USA) fitted with full spectrum bulbs (BlueMax

149 lamps, Full Spectrum Solutions, Jackson, MI, USA) positioned above the tank and within an

150 opaque curtain enclosure. The curtain (black canvas) was suspended from a rectangular plywood

151 frame placed $2 \mathrm{~m}$ above the top of the tank in order to exclude ambient light from entering the

152 set-up during all behavioral trials (Fig. 2a). Light intensity was varied by changing the height of

153 the lights above the water surface and using combinations of different neutral density filters

154 covering the lights (Lee Filters, Burbank, CA, USA). Light intensity (in lux [1x], lumen/m², and

155 photosynthetically active radiation [PAR], $\mu \mathrm{mol}$ photons $/ \mathrm{m}^{2} / \mathrm{s}$ ) and color spectrum were

156 measured using a spectrometer (range: 340-1028 nm, Jaz spectrometer, Ocean Optics, Dunedin,

157 FL, USA) connected to a 2 m optical fiber (QP400-2-UV/VIS, Ocean Optics) fitted with a cosine

158 corrector (CC-3, Ocean Optics). Water temperature was monitored during experiments and the

159 fluorescent bulbs did not raise the temperature of the experimental tank. 
Light intensities used in this study were based on the following data and calculations.

161 First, light levels present during sunrise/sunset to darkness are known for other freshwater

162 habitats (Harden Jones 1956; Ali 1959) and can range from 1000 lx (early twilight) to 0 lx (new

163

164

165

equation:

$$
I_{t}=I_{S} \times e^{-\varepsilon \times T}
$$

166

where $\mathrm{I}_{\mathrm{s}}$ and $\mathrm{I}_{t}$ are the light intensities at the surface $(\mathrm{S})$ and at depth $(\mathrm{T})$; and $\varepsilon$ is the light

167

extinction coefficient. The average light intensity at the surface of Lake Malawi at midday on a

168 clear sunny day is approximately $2000 \mu \mathrm{mol}$ photons $/ \mathrm{m}^{2} / \mathrm{s}(\sim 108,000 \mathrm{~lx})$. This photon flux was

169 derived from cloudless surface irradiance for Lake Malawi (Guildford et al. 2000). Using light

170 extinction coefficient of either $0.10 \mathrm{~m}^{-1}$ (Patterson et al. 2000), $0.13 \mathrm{~m}^{-1}$ (Guildford et al. 2007),

171 or $0.43 \mathrm{~m}^{-1}$ (Guildford et al. 2007) depending on location and season, the light intensity at many

172 depths can be estimated under these conditions (Table 1).

173 Full spectrum bulbs were used because they provide the range of wavelengths that 174 correspond to the range of known absorption peaks of retinal photopigments in species of 175 Aulonocara and Tramitichromis. For instance, absorption peaks for A. hueseri are at $415 \mathrm{~nm}$ 176 (violet), $484 \mathrm{~nm}$ (blue-green) and $526 \mathrm{~nm}$ (green; Jordan et al. 2006) and absorption peaks for $T$. 177 intermedius are at $455 \mathrm{~nm}$ (blue), $532 \mathrm{~nm}$ (green) and $569 \mathrm{~nm}$ (red; Parry et al. 2005). In the 178 experimental tank, full spectrum bulbs generated major and minor light peaks at 404, 435, 487, 179545,587 , and $611 \mathrm{~nm}$, and neutral density filters were used to change light intensity did not 180 appreciably change the light spectrum in the experimental tank (Fig. 2b) 
Experiments

Behavioral trials and video analysis of six well-defined behavioral parameters (number of prey strikes, detection distance, detection angle, detection-to-strike velocity, swimming phase [glide, pause] at detection and, prey type preference [order of prey strikes]) were carried out as in Schwalbe et al. (2012) and Schwalbe and Webb (2014) with slight modifications. A total of sixty trials were conducted using $A$. stuartgranti (30 trials, $n=6$ fish, 75-85 $\mathrm{mm}$ total length [TL], 4 females, 2 male) and Tramitichromis (30 trials, $n=6$ fish, 75-98 mm TL, 1 female, 5 males) in order to quantify variation in behavioral responses to live (mobile) and dead (immobile) prey (= tethered adult brine shrimp) at five light intensities between 0 and 800 lx.

Trials were conducted in an experimental tank $(120 \times 75 \times 60 \mathrm{~cm} ; 560 \mathrm{~L})$ with $5 \mathrm{~cm}$ of sand covering the bottom of the tank. Light intensity and spectral measurements (with \pm 0.01 accuracy, measured in $1 \mathrm{x}$ and PAR) were taken directly above the center of each mesh platform (to which live and dead prey were tethered, see below) before and after each trial, and light intensity and spectrum were found to be consistent at all six platforms and trials (Figs. 2b, c). Each fish was acclimated to a particular light intensity in the experimental tank for at least 30 minutes prior to a trial. The transition between photopic (cone-mediated) and scotopic (rodmediated) vision occurs at approximately $1 \mathrm{~lx}$, and light-adapted fish may take 30 minutes (and up to 3 hours) to become dark-adapted (Ali 1959). Thus, the $30+$ minute light adaptation period was judged to be sufficient to allow the fish's visual system to adjust to the light level for a given trial.

Before each trial, 12 adult brine shrimp (Artemia sp.) were tethered in pairs (1 live and 1 dead, freshly frozen) on each of six mesh platforms $(10 \times 10 \mathrm{~cm})$, which were positioned in a $2 \mathrm{x}$ 
2053 matrix so that the top of each platform flush with the sand surface. The water filtration system 206 for the experimental tank was then turned off to eliminate acoustic and hydrodynamic noise. At 207 the start of a trial, a fish was released into the experimental arena from behind an opaque divider 208 and feeding behavior was recorded for 30 min using an HD digital video camera (Sony C HDRCX550V, 30 frames per second) mounted directly above the tank, which provided a dorsal view of the experimental arena. Trials at 1-800 lx were carried out with standard fluorescent room 211 lights on for all but the lowest light levels (1-12 lx). Dark trials (0 lx) were conducted with room 212 lights off, but with infrared illumination (peak $=840 \mathrm{~nm}$, range 800-880 nm; Speco Provideo, 213 IR-200/24, Amityville, NY) to allow video recording of behavior.

Each fish was run through five trials, one trial per day each at a single light intensity, 215 progressing from highest to lowest intensity on subsequent days (e.g., 800, 112, 12, 1, and then 0 $216 \mathrm{~lx}$ ). Trials were carried out in this order to increase the likelihood that a fish would respond to 217 prey at lower light intensities (especially in the dark, 0 lx), as was suggested by preliminary 218 results. Trials were conducted over four months and the mean time between the first (800 lx) and 219 last (0 lx) trial for a given fish was 11 days (range = 6-19 days). "Light" trials (1-800 lx) started midday to late afternoon (11:00-17:00) and "dark" trials

221 (0 1x) took place shortly after sunset (19:00-21:00; soon after room lights had automatically shut 222 off; as in Schwalbe et al. 2012; Schwalbe and Webb 2014). Dark trials (0 1x) were not carried out 223 during the day (during the light phase of the lab's light:dark cycle) in order to avoid the 224 introduction of extraneous light. In addition, it was known that placing fish in low light or 225 darkness during normal daylight hours would disrupt feeding behavior (M.A.B. Schwalbe and A. 226 Mensinger, pers. obs.), and that species that normally feed both in full light during the day and at 
227 night (e.g., during the dark phase of a lab's light:dark cycle) were unresponsive in dark (0 1x) 228 trials carried out during the day.

To assess the number of prey detections that lead to prey strikes, unconsumed prey were counted at the end of each 30-minute trial and strike success was also confirmed in video recordings. Video sequences leading to each prey strike were exported to Premier Pro (Adobe,

232 CS5) for further analysis. Analysis of sequential video frames was used to identify the phase of

233 swimming behavior (thrust, glide, or pause) during which prey detections occurred. Detection

234 distance and detection angle were measured in these images using ImageJ (NIH, v. 1.41o).

235 Detection distance was defined as the distance from the tip of a fish's mouth to the prey,

236 measured in the frame immediately before the fish oriented towards it (e.g. before a turn defining

237 detection). For each prey strike, detection-to-strike velocity was calculated by dividing detection

238 distance by the time interval between detection and initiation of a strike. Detection angle was

239 measured in the same video frame in which detection distance was measured, and was defined as

240 the angle between a line extending anteriorly along midline of the fish (body axis) and a line

241 drawn from the prey to the tip of the fish's mouth.

242

243 Statistical analysis

245 Four of the six behavioral parameters were analyzed using generalized linear mixed models

246 (GLMMs; number of prey strikes, detection distance, detection-to-strike velocity, phase of

247 search behavior during which detections occurred). In addition, a ranking method (Taplin 2007)

248 was used to analyze prey preferences (live versus dead prey) and circular statistics were used to

249 analyze detection angles. All continuous data (e.g. detection distance and detection-to-strike 
velocity) were tested for normality (Kolmogorov-Smirnov test) and were $\log _{10}$ transformed to achieve normality (detection distance and detection-to-strike velocity). All statistical tests were considered significant at $P<0.05$ and values are given as means \pm s.e.m.

Start time (= time of day, 0-24 hr) for trials conducted at the five different light intensities was analyzed with nonparametric tests (e.g. Kruskal-Wallis test and Mann-Whitney U test) to determine whether time of day affected feeding behavior. This analysis showed that the times at which light trials (1-800 lx) and dark trials (0 1x) started did not differ between species (MannWhitney $\mathrm{U}$ test, $P>0.05$ ), but trial start time varied among light intensities in each species (Kruskal-Wallis test, A. stuartgranti: $K=22.804, P<0.001$; Tramitichromis: $K=20.141, P<$ 0.001). Thus, time of day (=trial start time) was included in all GLMM analyses. Four-way GLMM analyses (SPSS, IBM, v. 22) were used to test whether species ( $A$. stuartgranti, Tramitichromis), light intensity (0-800 lx), prey type (live, dead), and/or trial start time (0-24 hr) predict differences in each of four behavioral parameters (number of prey strikes, detection distance, detection-to-strike velocity, and phase of search behavior during which detections occurred). Three-way GLMM analyses were used to further examine whether light intensity, prey type, and/or trial start time predict differences in the four behavioral parameters in each species separately. The selection of random (individual) and fixed effects (species, light intensity, prey type, and trial start time), including repeated measures for the same individual, was addressed in all analyses. Different types of GLMMs were used to account for the different types of data collected in this study (summarized in Table 2) and the most parsimonious model was selected for each behavioral parameter based on the corrected Akaike information criterion (AICC). 
The order in which live (mobile) and dead (immobile) prey were struck was analyzed in

273 each species following Taplin (2007). This method assumes that when presented with equal

274 numbers of two or more types of prey, the order in which prey are consumed provides

275 information about prey preference - that prey consumed first are more highly preferred than prey

276 consumed second, third, etc. and the last prey consumed is the least preferred. While differences

277 in handling time, encounter rates, and relative mobility of prey can potentially complicate the

278 results of this sort of analysis (Durham et al. 2012, McWilliam et al. 2013), such variation was

279 minimized in the current study by offering equal numbers of live and dead brine shrimp tethered

280 in the same arrangement to platforms placed in a 2 × 3 matrix in all trials. The null hypothesis for

281 this analysis was that live and dead prey would be consumed randomly during a trial. Videos

282 were analyzed so that each prey consumed was assigned a rank number (first prey consumed=1,

283 second prey consumed=2, etc.), and any remaining prey were assigned an average of the

284 remaining preference scores, and considered "tied for last." A pair of preference scores for live

285 and dead prey at each light intensity was calculated for each fish. The pairs of scores from all of

286 the fish were considered independent samples and thus grouped by light intensity and species for

287 analysis. A score of 6.5 (based on presentation of six live and six dead prey, 12 total prey in a

288 trial) indicated no preference, a score of $<6.5$ revealed a preference for that prey type, and a score

289 of $>6.5$ indicated no preference or that prey type was ignored or avoided. Scores for live and

290 dead prey at each light intensity and for each species, were compared separately using paired $t$ -

291 tests (SPSS, IBM, v. 22).

292

Detection angles were analyzed with circular statistics (Oriana v. 3, Kovach Computing

293 Services, Anglesey, UK). Rayleigh tests were performed for each species to test whether

294 detections of live and dead prey at each of the five light intensities (0-800 lx) occurred at 
295 uniformly or non-uniformly distributed positions around the fishes' body relative to the body 296 axis (e.g. to define the receptive field). Watson's $U^{2}$ tests were used to determine if detection 297 angles differed with prey type and with light intensity within and between species.

\section{Results}

Aulonocara stuartgranti and Tramitichromis sp. actively swam around the experimental tank

302 during trials at all light intensities, including darkness (0 lx), and used a saltatory search strategy

303 (a cyclic sequence of a caudal fin thrust, glide, and pause) while exploring the tank. Of the 360

304 total prey presented to fish during all 60 trials, A. stuartgranti struck at 299 prey $(=83 \%)$ and

305 Tramitichromis struck at 231 prey (=64\%; see Figs. 3, 4). Prey were detected by both species

306 during a glide or a pause, but never during a thrust (see Fig. 5).

$307 \quad$ Four-way GLMM analyses (Table 3) indicated that species alone did not predict

308 differences in any of the four behavioral parameters (number of prey detections, detection

309 distance, detection-to-strike velocity, or swimming phase at prey detection), and that only the

310 interaction of species, light intensity, and prey type had a significant effect only on number of

311 prey detections. The interaction of light intensity and time of day predicted differences in all four

312 behaviors. Light intensity alone predicted differences in all four behaviors, and time of day

313 predicted differences in three behavioral parameters (number of prey detections, detection

314 distance, detection-to-strike velocity), but not in swimming phase at prey detection. Separate

315 three-way GLMM analyses for each species (Table 4, see below) revealed interesting trends that

316 are indicative of species differences in prey detection behavior. Analyses of prey preference (live 
317 vs. dead prey) and prey detection angle, carried out using other statistical methods, also indicated differences in behavior between species, but did not consider time of day.

GLMM analyses (Table 4) showed that light intensity did not significantly predict any of the four behavioral parameters in A. stuartgranti (number of prey detections, detection distance, 324 detection-to-strike velocity, or swimming phase at prey detection; GLMMs, $P>0.05$; Table 4).

325 However, time of day predicted the number of prey detections, and the interaction of time of day 326 and prey type predicted both detection distance and detection-to-strike velocity (GLMMs, $P<$ 327 0.05; Table 4). Neither light intensity, time of day, prey type, nor their interactions, predicted 328 swimming phase at prey detection. trends. A. stuartgranti struck at high numbers of both live (mobile) and dead (immobile) prey at 331 light intensities of 1-800 lx (Figs. 3a, 4a). They detected prey during a pause about half of the 332 time, but detected $61 \%$ of prey in a pause at the highest light intensity (800 lx; Fig. 5a).

333 Detection distance and detection-to-strike velocity appeared to not vary among light intensities 334 of $12-800 \mathrm{~lx}$, but fish tended to detect live prey from greater distances $($ mean $=8.7-9.6 \mathrm{~cm})$ than 335 dead prey $(6.0-6.9 \mathrm{~cm})$ and to detect live prey at higher detection-to-strike velocities $(9.7-10.4$ $336 \mathrm{~cm} / \mathrm{s})$ than dead prey $(6.9-7.4 \mathrm{~cm} / \mathrm{s}$; Figs. 4c, e). At $1 \mathrm{~lx}$, fish tended to detect live and dead prey 337 from similar distances (mean $=6.5$ and $6.3 \mathrm{~cm}$, respectively; Fig. $4 \mathrm{c}$ ) and similar detection-to338 strike velocities $(6.8 \mathrm{~cm} / \mathrm{s}$ and $7.8 \mathrm{~cm} / \mathrm{s}$, respectively; Fig. 4e). Live and dead prey (combined) were detected at non-uniformly distributed positions around the fishes' bodies at light intensities 
$340 \geq 11 \mathrm{x}$ (Rayleigh test, $P<0.001 ; \pm 90^{\circ}$ from body axis) with no differences in the distribution of 341 angles among pairs of light intensities with the exception of the two highest light intensities (112 $3421 \mathrm{x}$ versus 800 1x; Watson's $\mathrm{U}^{2}$ test, $\mathrm{U}^{2}=0.19, P<0.05$; Fig. 6a). Finally, fish tended to prefer 343 live prey at all light intensities, but only demonstrated a statistically significant preference for 344 live prey at 112 lx, but not at 800 lx (Table 5; Fig. 7a), which is not easily explained.

345 In the dark (0 lx), prey detection behavior of $A$. stuartgranti was different than at light 346 intensities $\geq 11 \mathrm{~lx}$. Fish struck at only 22 prey ( $=30.6 \%$ of total prey presented; Fig. 3a), and 347 tended to detect prey at even shorter distances (Fig. 4c) and at slower detection-to-strike 348 velocities (Fig. 4e) than when at least some light was present. Fish tended to detect more live 349 prey than dead prey (mean of 2.7 and 1.0, respectively; Figs. 3a, 4a), showed a statistically 350 significant preference for live prey (Table 5, Fig. 7a), and detected live prey from more than 351 twice the distance than dead prey (3.2 and $1.4 \mathrm{~cm}$, respectively; Fig. 4c). In addition, detection352 to-strike velocity at $01 \mathrm{x}$ was about one half of that at higher light intensities $(\sim 3.5-5 \mathrm{~cm} / \mathrm{s}$ at $01 \mathrm{x}$ 353 versus $\sim 7-10 \mathrm{~cm} / \mathrm{s}$ at $\geq 1 \mathrm{~lx}$ ), but fish tended to detect live prey at somewhat higher detection-to354 strike velocities than dead prey (Fig. 4e). In the dark, 95\% of prey were detected during a glide 355 and only a few prey (5\%) were detected during a pause (Fig. 5a). Prey (live and dead combined) 356 were detected at positions uniformly distributed around fishes' bodies (Rayleigh test, $P>0.05$ ) 357 at a wide range of angles $\left( \pm 180^{\circ}\right.$ from body axis, Fig. $\left.6 a\right)$, but the distribution of detection 358 angles did not differ for live versus dead prey (Watson's $\mathrm{U}^{2}$ test, $P>0.05$ ). 
362 GLMM analyses (Table 4) showed that, in contrast to A. stuartgranti, the interaction of light intensity and time of day predicted three of four behavioral parameters (number of prey detections, detection distance, and detection-to-strike velocity). As in A. stuartgranti, neither light intensity, time of day, nor prey type, or their interactions, predicted swimming phase at prey detection. Prey type did not predict any of the four behavioral parameters in Tramitichromis, and the interaction of light intensity and prey type predicted only detection distance (Table 4). Tramitichromis tended to strike at high numbers of prey (Fig. 3b, 4b), and $>60 \%$ of prey (live and dead, combined) were detected during a pause at light intensities of 1-800 lx (Fig. 5b). At

371 light intensities of 12-800 lx, fish struck at live and dead prey from similar, long detection 372 distances (means $=9.8-10.1$ and $8.5-10.0 \mathrm{~cm}$, respectively) and at high detection-to-strike 373 velocities (9.6-10.5 and 8.7-9.3 cm/s, respectively). In contrast, at $1 \mathrm{~lx}$, fish tended to strike at 374 both live and dead prey at similar, but shorter detection distances (6.9 and 6.3, respectively) and 375 lower detection-to-strike velocities (7.0 and 6.1, respectively; Figs. 4d, f) than at higher light 376 intensities. Both live and dead prey were detected at non-uniform positions around the body 377 (Rayleigh test, $P<0.001$ ), which defined a very narrow range of detection angles from the body 378 axis $\left( \pm 40^{\circ}\right)$; distributions were the same for live prey and dead prey at light intensities of 1-800 $3791 \mathrm{x}$ (Watson's $\mathrm{U}^{2}, P>0.05$; Fig. 6b). Fish tended to prefer live prey at different light intensities, 380 but only showed a statistically significant preference for live prey at the highest light intensity 381 (800 lx; Table 5; Fig. 7b).

383 of the 72 prey presented). These strikes are likely to have been the result of random encounters 384 with prey as opposed to being the result of active search and directed strikes. 
Discussion

The multiple statistical analyses presented here, and the detailed examination of trends in the detection of live and dead prey at different light intensities in each species indicate that light intensity affects prey detection behavior in different ways in Aulonocara stuartgranti and Tramitichromis.

Prey type and/or time of day, but not light intensity, were predictors of three of the four behavioral parameters (number of prey detections, detection distance, and detection-to-strike

397 velocity) analyzed using GLMMs in A. stuartgranti. The lack of significance for light intensity is 398 consistent with the use of lateral line cues (see also Schwalbe et al. 2012), but also suggests that 399 A. stuartgranti may use a light-independent circadian rhythm to interpret time of day. This is 400 consistent with the occurrence of Aulonocara species at depths up to120 $\mathrm{m}$ in Lake Malawi 401 where light is limited or absent (Konings 1990, 2007) and in caves where spawning has been 402 reported (Grant et al. 1987), and thus where normal diurnal variation in light intensity may not be 403 a consistent or reliable cue for the regulation of behavior. The significance of prey type as a 404 predictor of detection distance and detection-to-strike velocity is illustrated by apparent 405 differences in numbers of live and dead prey detected at the same light intensities (Fig. 4; see 406 also Schwalbe et al. 2012; Schwalbe and Webb 2014), the tendency to prefer live prey at all light 407 intensities, and the statistically significant preference for live prey in the dark. 
In contrast, in Tramitichromis, it is the interaction of light intensity and time of day that

409

410

411

412

413

414

415

416

417

predict these same three behavioral parameters. The importance of light intensity not surprising because Tramitichromis uses visual, but not lateral line cues, for prey detection and does not feed in the dark (Schwalbe and Webb 2014). Furthermore, these two factors are correlated both in the lab where the fish were reared (on a 12:12 hr light/dark cycle) as well as in the relatively shallow waters in their natural habitat in Lake Malawi, which is just $9-17^{\circ}$ south of the equator where fish experience 11-13 hours of daylight per day on an annual basis (http://astro.unl.edu). Thus, these fish have evolved and are reared in environments where light intensity and time of day are tightly correlated. The independent roles of these two factors in predicting behavior would need to be addressed in additional experiments, which were out of the scope of this study.

Swimming phase (glide, pause) during which prey were detected was predicted neither by light intensity nor by time of day in either species. The ability to detect prey during a glide or pause will affect both the stabilization of the visual field (for vision-mediated detection) and/or the magnitude of environmental and self-generated hydrodynamic noise (for lateral linemediated detection). A. stuartgranti and Tramitichromis both detected between $40 \%$ and $70 \%$ of prey during a pause at light intensities of $\geq 11 x$, suggesting the importance of stabilizing the visual field for prey detection at these light intensities. Prey type (which defines the presence or absence of an additional visual motion stimulus) did not predict swimming phase at detection for Tramitichromis $(P<0.053)$, but a larger sample size may have yielded a different statistical outcome. Prey type also did not predict swimming phase at prey detection for A. stuartgranti, but the shift to $95 \%$ of prey detections during a glide in the dark (where stabilization of visual field is irrelevant), and their preference for live prey (that generate hydrodynamic flows detected in the dark; Schwalbe and Webb 2014), are important indicators of the overall importance of prey type. 
431 A. stuartgranti detected live prey at distances of less than half of a body length and at lower

432 detection-to-strike velocities at a low light intensity (1 lx) and in the dark (0 lx). In the presence

433 of at least some light, lower detection-to-strike velocities would also reduce self-generated

434 hydrodynamic noise (Montgomery et al. 2009), enhancing lateral line-mediated prey detection,

435 which would suggest that fish would tend to detect prey during a pause. However, the high

436 proportion of detections $(95 \%)$ at relatively low detection-to-strike velocities, while not

437 eliminating self-generated noise, would bring a fish into the vicinity of potential prey that are

438 generating detectable hydrodynamic flows (Schwalbe et al. 2012).

439

440

Role of vision and critical light intensities

441

442

The importance of vision in A. stuartgranti and Tramitichromis is further supported by a

443 consideration of critical light intensities and the potential differences in the use of binocular

444 vision. Prey detection at relatively long distances is consistent with vision-mediated prey

445 detection in fishes (Vinyard and O'Brien 1976, Confer et al. 1978, Henderson and Northcote

446 1985, Mazur and Beauchamp 2003), and at higher light intensities detection of free swimming

447 prey generally occurs at longer distances (Vinyard and O'Brien 1976; Richmond et al. 2004;

448 Bergstrom and Mensinger 2009). In this study, both A. stuartgranti and Tramitichromis tended to

449 demonstrate the longest detection distances at the highest light intensities, which is thus

450 consistent with vision-mediated prey detection. Detection distances may not increase as light

451 intensity increases further in a given species (Schmidt and O'Brien 1982), but may decrease

452 sharply below a "critical light intensity" (Confer et al. 1978). Trends in behavioral parameters in

453 the current study reveals that the critical light intensity for fish feeding on tethered adult brine 
454 shrimp is between 12 and 1 lx for both $A$. stuartgranti and Tramitichromis. This is comparable to 455 the critical light intensities for other freshwater teleosts in studies feeding on free-swimming 456 Daphnia (11-50 lx, in bluegill, Vinyard and O'Brien 1976; in lake trout, brook trout, and 457 bluegill, Confer et al. 1978), amphipods (5-25 1x, in round goby, logperch, slimy sculpin, and 458 spoonhead sculpin, Bergstrom and Mensinger 2009), or on small fish ( 6-18 1x, in largemouth 459 bass, Howick and O’Brien 1983; lake trout, Vogel and Beauchamp 1999). At low light 460 intensities (below the critical intensity, at 1 lx), the ability of $A$. stuartgranti to detect more prey 461 than Tramitichromis, but at comparable distances suggests that $A$. stuartgranti may have superior 462 visual abilities for prey capture at these lower light intensities. This is consistent with their 463 distribution at a wider depth range than Tramitichromis and the observation of reproductive 464 behaviors in caves (Grant et al. 1987), but whether Aulonocara species possess adaptations for 465 increased sensitivity and/or visual acuity as found in known crepuscular or nocturnal teleosts 466 (reviewed in Warrant 2004; Schmitz and Wainwright 2011) requires further study. The potential for binocular vision can be revealed by looking at behavioral evidence for 468 differences in the size of visual fields under different light conditions and between species. 469 While visual predators may respond differently to stimuli in different portions of their visual 470 fields (Collin 1989; McComb and Kajiura 2007; Miyazaki et al. 2011), it is detection angle that 471 is reflects the overall size of the visual field, which is defined by the size, shape, and position of 472 the eyes (Collin and Shand 2003). A. stuartgranti demonstrates a wide range of detection angles 473 at light intensities $\geq 1 \mathrm{~lx}\left( \pm 90^{\circ}\right.$ from body axis $)$ and an even wider range of angles in darkness $(0$ $4741 \mathrm{x}, \pm 180^{\circ}$ from body axis). This shift is correlated with differences in behavioral parameters at 1 475 lx versus 0 lx, which are interpreted as a shift between primarily vision-mediated prey detection 476 to lateral line-mediated prey detection. Lateral line-mediated detection of prey around the body is 
477 enabled by the more sensitive widened cranial lateral line canals that characterize Aulonocara

478 species, and by the broad distribution of canal and superficial neuromasts on the skin of the head,

479 trunk and tail, which is typical of cichlids and of most teleosts (reviewed in Webb 2014). In

480 contrast, Tramitichromis detected prey at a range of angles ( $\pm 40^{\circ}$ from body axis) that was less

481 than half of that for $A$. stuartgranti ( $\pm 90^{\circ}$ from body axis) at light intensities of 1-800 lx, with

482 one exception (Watson's $\mathrm{U}^{2}$ test, $\mathrm{P}<0.05$ ). This suggests that Tramitichromis, but likely not $A$.

483 stuartgranti, uses binocular vision and depth perception to detect prey at a distance (as

484 demonstrated in other teleosts, Sivak 1978; Blanco-Vives et al. 2011; Miyazaki et al. 2011).

485 Furthermore, Tramitichromis tends to swim higher above the substrate than $A$. stuartgranti when

486 searching for prey in the laboratory (Schwalbe and Webb 2014). Coupled with the use of

487 binocular vision, this search strategy could explain the tendency for Tramitichromis to detect

488 benthic prey at somewhat longer distances than $A$. stuartgranti (Figs. 4c, d).

The movements of the appendages of the live prey used in this study presumably generate 490 a visual motion stimulus, and an enhanced dispersal of an odor plume (not evaluated here), in

491 addition to a hydrodynamic stimulus, which addresses the importance of multimodal integration

492 in the formulation of prey detection behavior. However, prey type predicted detection distance

493 and detection-to-strike velocity only in A. stuartgranti, which tended to strike at live prey at

494 longer detection distances and at higher velocities than for dead prey at the same light intensities

495 (12-800 1x). At 1 1x, detection distances were about one body length or less, which is within the

496 effective range of the lateral line system (Coombs 1999). Behavior is consistent with the use of

497 the lateral line system in addition to vision for detection of live prey by $A$. stuartgranti in full

498 light. 
In contrast, in Tramitichromis, prey type did not predict any of the four behavioral parameters analyzed using GLMMs, although the interaction of prey type and light intensity did predict detection distance. However, the examination of data trends showed that Tramitichromis demonstrates comparable values and trends for live and dead prey with reference to number of prey detections, detection distance (despite the significance of its interaction with prey type) and detection-to-strike velocity at light intensities of 1-800 lx. These results also substantiate results of a prior laboratory study (Schwalbe and Webb 2014) that showed that Tramitichromis is a visual predator, which is not dependent on the detection of hydrodynamic stimuli generated by live prey. However, the lack of significance of prey type indicates that Tramitichromis does not respond to a visual motion stimulus that are likely to have been generated by live (but not dead) prey, which is surprising given the feeding strategies that these fish employ in nature. In the relatively shallow, well-lit waters of Lake Malawi, Tramitichromis species typically capture prey by plunging into the substrate, filling their mouth with sand, and sifting out prey with their gill rakers (= sand sifting, Fryer 1959). The sensory basis for the plunge and sift feeding behavior needs to be determined experimentally, but the results of this study suggest that it is a visual stimulus and not an associated motion stimulus generated by live prey that influences where Tramitichromis initiates feeding behavior in the field.

\section{The connection between experimental light conditions and light levels in Lake Malawi}

As in other lakes, the photic conditions in Lake Malawi are dynamic and many factors influence the light environment, including habitat type, water depth, and proximity to the lake bottom (Sabbah et al. 2011), as well as meteorological events, eutrophication, turbidity, and both diurnal 
522 and seasonal changes in light quality and quantity. In shallow water, full spectrum light is

523 typically present and middle wavelengths transmit best, but shorter and longer wavelengths

524 attenuate rapidly (Dalton et al. 2010). Further, the irradiance spectrum differs between waters

525 overlying sandy and rocky substrates, where light transmission in water above sand is shifted to

526 longer wavelengths compared to that above rocky habitats (Sabbah et al. 2011).

527 The extent to which species of Aulonocara and Tramitichromis forage using vision at

528 different depths can be approximated by comparing behavioral data from the current study to

529 estimates of depths at which particular light intensities are predicted to occur in Lake Malawi.

530 The light extinction coefficients in Table 1 are representative of pelagic $\left(\varepsilon=0.10 \mathrm{~m}^{-1}\right.$, Patterson

531 et al. 2000; $\varepsilon=0.13 \mathrm{~m}^{-1}$, Guildford et al. 2007) and nearshore ( $\varepsilon=0.43 \mathrm{~m}^{-1}$, Guildford et al.

532 2007) habitats in Lake Malawi, but disparities in water clarity between these areas are likely

533 influenced by nutrient loading and sedimentation from deforestation, intense agricultural

534 practices, and erosion in nearshore areas (Bootsma and Jorgensen 2006). Estimations based on

535 low light extinction coefficients (e.g. $\varepsilon=0.10 \mathrm{~m}^{-1}$ or $0.13 \mathrm{~m}^{-1}$ ) suggest that Aulonocara species

536 could visually detect prey at 71 to $92 \mathrm{~m} \mathrm{(} \geq 12 \mathrm{~lx})$ and with some visual limitations at $\sim 89$ to 115

$537 \mathrm{~m}$ where light levels are at $\sim 1 \mathrm{~lx}$. Some Aulonocara species are found to depths of $120 \mathrm{~m}$

538 (Konings 2007), so they may be able to visually detect prey in these depths at midday when light

539 intensities are highest. Alternatively, when light extinction coefficients are used $\left(\varepsilon=0.43 \mathrm{~m}^{-1}\right)$,

540 the maximum depths at which Aulonocara species could reliably detect prey are greatly reduced

541 (to $21 \mathrm{~m}$ and $27 \mathrm{~m}$, respectively). In the lab, Tramitichromis was able detect prey at a light

542 intensity of $1 \mathrm{~lx}$, which translates to depths of 89 to $115 \mathrm{~m}$ if the light extinction coefficient is

543 low. However, these fish are typically found in shallower waters ( $<15 \mathrm{~m}$, Konings 1990, 2007),

544 so the ability of Tramitichromis to find prey at $1 \mathrm{~lx}$ is more relevant for the potential for feeding 
545 early or late during the day. Given its dependence on vision for prey detection (Schwalbe and

546 Webb 2014), Tramitichromis species may be limited to shallow habitats so that the visual

547 detection of prey is not compromised. In contrast, Aulonocara species can feed at low light

548 intensities and in the dark, which can explain the wider range of depths at which they occur in

549 Lake Malawi. They may also be crepuscular or nocturnal in habit, which may also facilitate other

550 behaviors (e.g., social interactions) at low light intensities.

551

552 Conclusions

553

554 A. stuartgranti fed on prey at a range of ecologically relevant light intensities, including

555 darkness, and Tramitichromis was also able to feed at low light intensities, but not in darkness.

556 In A. stuartgranti, the influence of time of day on several aspects of its behavior suggests that it

557 may use circadian rhythms to regulate behavior in nature where diurnal light cues may not be

558 available (e.g. at greater depth, in caves). The integration of visual and non-visual (e.g., lateral

559 line) sensory modalities can explain the statistically non-significant trends in behavior. Similarly, 560 the dramatic change in behavior from $11 \mathrm{x}$ to $01 \mathrm{x}$ is consistent with a transition from primarily

561 vision-mediated to exclusively lateral line-mediated prey detection behavior. In contrast to $A$.

562 stuartgranti, Tramitichromis depends on vision-mediated prey detection (Schwalbe and Webb

563 2014); in this study its behavior was significantly affected by the interaction of light intensity

564 with time of day, but these two factors could not be teased apart. Finally, in an ecological

565 context, the tendency of Tramitichromis species to live in shallower, well-lit habitats, in contrast

566 to Aulonocara species, which live at a wide range of depths and light environments, suggests that

567 sensory capabilities may allow Aulonocara species to escape competition with Tramitichromis 
568 species for prey resources, thus facilitating niche differentiation between these taxa. Field 569 observations in Lake Malawi are needed to test this hypothesis, which would provide an

570 important link between the morphology, feeding behavior, and ecology of cichlid fishes.

571

\section{Acknowledgements}

573

574 We thank Karen Carleton (University of Maryland) for her expertise in cichlid vision, Stephanie

575 Guildford (University of Minnesota Duluth) for her expertise on light levels in Lake Malawi, and 576 Graham Forrester (University of Rhode Island) for statistical expertise. We also thank Edward

577 Baker (Facilities Manager, RI NSF EPSCoR Marine Life Science Facility), Emily Becker,

578 Brandon Fuller, Christopher Holland, Callie Veelenturf, Rebecca Scott, and Benjamin Sevey for 579 assistance with fish husbandry, Christopher Kenaley (Harvard University) for doing the $\mu \mathrm{CT}$ 580 scans, and Benjamin Sevey for generating the 3D images in Fig. 1. This work was carried out 581 under an approved University of Rhode Island IACUC protocol (\#AN08-11-005). This research

582 was assisted by funds provided by NSF EPSCoR Cooperative Agreement EPS-0554548 and 583 EPS-100405, the College of the Environment and Life Sciences (University of Rhode Island) and 584 was supported by NSF grant IOS 0843307 to JFW.

\section{References}

Ali MA (1959) The ocular structure, retinomotor and photobehavioral responses of juvenile pacific salmon. Can J Zoology 37:965-996 
Atema J (1971) Structures and functions of the sense of taste in the catfish (Ictalurus natalis). Brain Behav Evol 4:273-294

Batty RS, Blaxter JHS, Libby DA (1986) Herring (Clupea harengus) filter-feeding in the dark. Mar Biol 91:371-375

Bergstrom MA and Mensinger AF (2009) Interspecific resource competition between the invasive round goby and three native species: logperch, slimy sculpin, and spoonhead sculpin. Trans Am Fish Soc 138:1009-1017

Blanco-Vives B, Aliago-Guerrero M, Cañavate JP, García-Mateos G, Martín-Robles AJ, Herrera-Pérez P, Muñoz-Cueto JA, Sánches-Vázquez FJ (2011) Metamorphosis induces a light-dependent switch in Senegalese sole (Solea senegalensis) from diurnal to nocturnal behavior. J Biol Rhythms 27:135-144

Bootsma H, Jorgensen SE (2005) Lake Malawi/Nyasa: Experience and lessons learned brief. pp 259-276. In: companion CD-ROM for: ILEC (2005). Managing lakes and their basins for sustainable use: A report for lake basin managers and stakeholders. International Lake Environment Committee Foundation, Kusatsu, Japan

Collin SP (1989) Topographic organization of the ganglion cell layer and intraocular vascularization in the retinae of two reef teleosts. Vision Res 29:765-775

Collin SP, Shand J (2003) Retinal sampling and the visual field in fishes. In: Collin SP, Marshall NJ (eds) Sensory processing in aquatic environments. Springer, New York, pp 139-169

Confer JL, Howick GL, Corzette MH, Kramer SL, Fitzgibbon S, Landesberg R (1978) Visual predation by planktivores. Oikos 31:27-37

Coombs S (1999) Signal detection theory, lateral-line excitation patterns and prey capture behaviour of mottled sculpin. Anim. Behav. 58: 421-430 
613 Dalton BE, Cronin TW, Marshall NJ, Carleton KL (2010) The fish eye view: are cichlids conspicuous? J Exp Biol 213:2243-2255

615 616

617

618

619

620

621

622

623

624

625

626

627

628

629

630

631

632

633

634

635

Denton EJ, Gray JAB (1988) Mechanical factors in the excitation of the lateral lines of fish. In: Atema J, Fay RR, Popper AN, Tavolga WN (eds) Sensory biology of aquatic animals. Springer. New York, pp 595-617

Denton EJ, Gray JAB (1989) Some observations on the forces acting on neuromasts in fish lateral line canals. In: Coombs S, Gorner P, Münz H (eds) The mechanosensory lateral ine: neurobiology and evolution. Springer, New York, pp 229-246

Diehl S (1988) Foraging efficiency of three freshwater fishes: effects of structural complexity and light. Oikos 53:207-214

Dunbrack RL, Dill LM (1984) Three-dimensional prey reaction field of the juvenile coho salmon (Oncorhynchus kisutch). Can J Fish Aquat Sci 41:1176-1182

Durham SR, Dietl GP, Visaggi CC (2012) The mismeasure of behavior: a natural history revision of prey preference in the banded tulip snail. J Shellfish Res 31:101-109

Fryer G (1959) The trophic interrelationships and ecology of some littoral communities of Lake Nyasa with especial reference to the fishes, and a discussion of the evolution of a group of rock-frequenting Cichlidae. Proc Zool Soc Lond 132:153-281

Fryer G, Iles TD (1972) The cichlid fishes of the great lakes of Africa: their biology and evolution. Oliver and Boyd, Edinburgh

Gardiner JM, Motta PJ (2012) Largemouth bass (Micropterus salmoides) switch feeding modalities in response to sensory deprivation. Zoology 115: 78-83

Grant SM, Dieckhoff HW, Mayland HJ, Meyer MK (1987) Ecology of Aulonocara Regan, 1922 in Lake Malawi. Cour. Forsch.-Inst. Senckenberg 94:131-139 
636 Guildford SJ, Bootsma HA, Fee EJ, Hecky RE, Patterson G (2000) Phytoplankton nutrient status

637

638

639

640

641

642

643

644

645

646

647

648

649

650

651

652

653

654

655

656

657 and mean water column light intensity in Lakes Malawi and Superior. Aquat Ecosyst Health 3:35-45

Guildford SJ, Bootsma HA, Taylor WD, Hecky RE (2007) High variability of phytoplankton photosynthesis in response to environmental forcing in oligotrophic Lake Malawi/Nyasa. J Great Lakes Res 33:170-185

Harden Jones, FR (1956) The behaviour of minnows in relation to light intensity. J Exp Biol $33: 271-281$

Henderson MA, Northcote TG (1985) Visual prey detection and foraging in sympatric cutthroat trout (Salmo clarki clarki) and dolly varden (Salvelinus malma). Can J Fish Aquat Sci 42:785-790

Hofmann CM, O’Quin KE, Marhsall NJ, Cronin TW, Seehausen O, Carleton KL (2009) The eyes have it: regulatory and structural changes both underlie cichlid visual pigment diversity. PLOS Biol 7(12):e1000266

Holbrook SJ, Schmitt RJ (1984) Experimental analyses of patch selection by foraging black surfperch (Embiotoca jacksoni Agazzi). J Exp Mar Biol Ecol 79:39-64

Howick GL, O’Brien WJ (1983) Piscivorous feeding behavior of largemouth bass: experimental analysis. Can J Fish Aquat Sci 42:785-790

Janssen J (1997) Comparison of response distance to prey via the lateral line in the ruffe and yellow perch. J Fish Biol 51:921-930

Jordan R, Kellogg K, Howe D, Juanes F, Stauffer J, Loew E (2006) Photopigment spectral absorbance of Lake Malawi cichlids. J Fish Biol 68:1291-1299 
658 Kirk JTO (2011) Light and photosynthesis in aquatic ecosystems, 3rd edn. Cambridge University

659

660

661

662

663

664

665

666

667

668

669

670

671

672

673

674

675

676

677

678

679

680

Press, New York

Konings A (1990) Koning's book of cichlids and other fishes of Lake Malawi. TFH Publications

Inc., Neptune City, New Jersey

Konings A (2007) Malawi cichlids in their natural habitat, 4th edn. Cichlid Press, El Paso, Texas

Laur DR, Ebeling AW (1983) Predator-prey relationships in surfperches. Env Biol Fish 8:217229

Lythgoe JN (1979) The ecology of vision. Clarendon Press, Oxford

Mazur MM, Beauchamp DA (2003) A comparison of visual prey detection among species of piscivorous salmonids: effects of light and low turbidities. Environ Biol Fish 67:397-405

McComb DM, Kajiura SM (2008) Visual fields of four batoid fishes: a comparative study. J Exp Biol 211:482-490

McWilliam RA, Minchinton TE, Ayre DJ (2013) Despite prolonged association in closed populations, an intertidal predator does not prefer abundant local prey to novel prey. Biol J Linn Soc 108:812-820

Miyazaki T, Iwami T, Meyer-Rochow VB (2011) The position of the retinal area centralis changes with age in Champsocephalus gunnari (Channichthyidae), a predatory fish from coastal Antarctic waters. Polar Biol 34:1117-1123

Moller P (2002) Multimodal sensory integration in weakly electric fish: a behavioral account. J Physiology-Paris 96: 547-556

Montgomery JC, Bleckmann H, Coombs S (2014) Sensory ecology and neuroethology of the lateral line. In: Coombs S, Bleckmann H, Fay RR, Popper AN (eds) The lateral line system. Springer, New York, pp 121-150 
Montgomery JC, Coombs S (1992) Physiological characterization of lateral line function in the Antarctic fish Trematomus bernacchii. Brain Behav Evol 40:209-216

Montgomery JC, Diebel C, Halstead MBD, Downer J (1999) Olfactory search tracks in the Antarctic fish Trematomus bernacchii. Polar Bio 21:151-154

Montgomery JC, McDonald F, Baker CF, Carton AG, Ling N (2003) Sensory integration in the hydrodynamic world of rainbow trout. Roy Soc Lond B Bio 270(2): S195-S197

Montgomery JC, Windsor S, Basset D (2009) Behavior and physiology of mechanoreception: separating signal and noise. Integr Zool 4:3-12

Parry JWL, Carleton KL, Spady T, Carboo A, Hunt DM, Bowmaker JK (2005) Mix and match color vision: tuning spectral sensitivity by differential opsin gene expression in Lake Malawi cichlids. Curr Biol 15:1734-1739

Partridge BL, Pitcher TJ (1980) The sensory basis of fish schools: relative roles of lateral line and vision. J Comp Physiol 135: 315-325

Parzefall J (1993) Behavioural ecology of cave-dwelling fishes. In: Pitcher T (ed) Behaviour of teleost fishes, 2nd edn. Chapman \& Hall, London, pp 573-608

Patterson G, Hecky RE, Fee EJ (2000) Effect of hydrological cycles on planktonic primary productivity in Lake Malawi/Niassa. Adv Ecol Res 31:421-430

Richmond HE, Hrabik TR, Mensinger AF (2004) Light intensity, prey detection and foraging mechanisms of age 0 year yellow perch. J Fish Biol 65:195-205

Rickel A, Genin A (2005) Twilight transitions in coral reef fish: the input of light-induced changes in foraging behaviour. Anim Behav 70:133-144

Ryer CH, Olla BL (1999) Light-induced changes in the prey consumption and behavior of two juvenile planktivorous fish. Mar Ecol Prog Ser 181:41-51 
Sabbah S, Gray SM, Boss ES, Fraser JM, Zatha R, Hawryshyn CW (2011) The underwater photic environment of Cape Maclear, Lake Malawi: comparison between rock- and sandbottom habitats and implications for cichlid fish vision. J Exp Biol 214:487-500

Schmidt D, O’Brien WJ (1982) Planktivorous feeding ecology of arctic grayling (Thymallus arcticus). Can J Fish Aquat Sci 39:475-482

Schmitt R, Holbrook SJ (1984) Ontogeny of prey selection by black surfperch Embiotoca jacksoni (Pisces: Embiotocidae): the roles of fish morphology, foraging behavior, and patch selection. Mar Ecol Prog Ser 63:6-12

Schmitz L, Wainwright PC (2011) Nocturnality constrains morphological and functional diversity in the eyes of reef fishes. BMC Evol Biol 11:338

Schwalbe MAB, Bassett DK, Webb JF (2012) Feeding in the dark: lateral-line-mediated prey detection in the peacock cichlid Aulonocara stuartgranti. J Exp Biol. 215:2060-2071

Schwalbe MAB, Webb, JF (2014) Sensory basis for detection of benthic prey in two Lake Malawi cichlids. Zoology 117:112-121

Sivak JG (1978) The functional significance of the aphakic space of the fish eye. Can J Zool $56: 513-516$

Taplin RH (2007) Experimental design and analysis to investigate predator preferences for prey. J Exper Mar Biol Ecol 344:116-122

Townsend CR, Risebrow AJ (1982) The influence of light level on the functional response of a zooplanktonivorous fish. Oecologia 53:293-295

Vinyard GL, O'Brien WJ (1976) Effects of light and turbidity on reaction distance of bluegill (Lepomis macrochirus). J Fish Res Board Can 33:2845-2849 
726 Vogel JL, Beauchamp DA (1999) Effects of light, prey size, and turbidity on reaction distances of lake trout (Salvelinus namaycush) to salmonid prey. Can J Fish Aquat Sci 56:1293-

728 1297

729 Warrant EJ (2004) Vision in the dimmest habitats on Earth. J Comp Physiol A 190:765-789

730 Webb JF (2014) Morphological diversity, development, and evolution of the mechanosensory 731 lateral line system. In: Coombs S, Bleckmann H, Fay RR, Popper AN (eds) The lateral

732 line system. Springer, New York, pp 17-72

733 Webb JF, Montgomery JC, Mogdans J (2008) Bioacoustics and the lateral line system of fishes. 734 In: Webb JF, Fay RR, Popper AN (eds) Fish Bioacoustics. Springer, New York, pp 145735 182 


\section{Figure Legends}

Fig. 1 Lateral line canals and canal neuromasts in Aulonocara stuartgranti (widened canals) and Tramitichromis (narrow canals) visualized using fluorescent vital staining (4-di-2-ASP, $63 \mu \mathrm{M}, 5$ min; a, c), $\mu \mathrm{CT}$ imaging (reconstructed from $14 \mu \mathrm{m}$ slices; $\mathbf{b}, \mathbf{d}, \mathbf{e}, \mathbf{g}, \mathbf{h}$ ), and scanning electron microscopy (f). a Lateral view of $A$. stuartgranti revealing series of larger infraorbital (IO), mandibular (MD), and preopercular (PO) canal neuromasts and very small superficial neuromasts on the skin (juvenile, $25 \mathrm{~mm}$ standard length [SL]). Neuromast number and distribution is the same in Tramitichromis $\mathbf{b} \mu \mathrm{CT}$ reconstruction of $A$. stuartgranti (adult, $78 \mathrm{~mm}$ SL) indicating the location of the supraorbital (SO), IO, MD, and PO canals in dermatocranial bones. c Ventral view of the head of $A$. stuartgranti (juvenile, $28 \mathrm{~mm} \mathrm{SL}$ ), revealing canal neuromasts in the MD and PO canals. d A. stuartgranti (adult, $78 \mathrm{~mm} \mathrm{SL}$ ) and e Tramitichromis (adult, $79 \mathrm{~mm} \mathrm{SL}$ ) in ventral view. Asterisks (*) denote the locations of the MD and PO canal neuromasts, as visualized in c; canal neuromasts are found in floor of the canal, between canal pore positions in the canal roof. Note the much larger pores in A. stuartgranti (d) than in Tramitichromis (e). f MD canal neuromast in a juvenile $A$. stuartgranti. Ciliary bundles of the sensory hair cells are evident in an elongate sensory strip in the middle of the diamond-shaped neuromast. Double-headed arrow below the sensory strip indicates the axis of physiological sensitivity of the hair cells, as well as the long axis of the canal in which the neuromast is found.

Scale bar $=10 \mu \mathrm{m} . \mathbf{g}$ A. stuartgranti and $\mathbf{h}$ Tramitichromis in frontal-ventral view with the pores of the SO, IO, MD, and PO canals that are directed ventrally, toward the source of stimuli generated by benthic prey. The pores on the right side of each fish in $\mathbf{g}$ and $\mathbf{h}$ have been enhanced to increase their visibility. 
761 Fig. 2 Experimental setup and light conditions used to record feeding behavior of $A$. stuartgranti 762 and Tramitichromis. a Diagram of experimental tank with front panel of light curtain removed.

763 Light sources originate from two fluorescent light fixtures (full spectrum light) and two infrared 764 (IR) lights. b Sample light spectra generated by fluorescent lights in behavioral trials. The y-axis 765 was compressed to illustrate peaks in the visual spectrum $(400-700 \mathrm{~nm})$ that occurred in $1-800 \mathrm{~lx}$ 766 trials. These peaks were consistent when light intensity was decrease with the addition of neutral 767 density filters among trials (see Table 1). The peak at $840 \mathrm{~nm}$ is from two IR lights in 0 and $11 \mathrm{x}$ 768 trials only. c Mean ( \pm s.e.m.) light intensities measured before and after trials indicating that light 769 intensity did not differ before and after trials at any of the light intensities used (students $t$-test, $P$ $770>0.05)$

771

772 Fig. 3 Total number of prey detections by prey type (white bars = live tethered brine shrimp, 773 grey bars $=$ dead tethered brine shrimp) for a $A$. stuartgranti $(n=6$ fish $)$ and b Tramitichromis $(n$ $774=6$ fish) at five different light intensities. Maximum number of possible prey detections $=72$ for 775 each light intensity

776

777 Fig. 4 Three behavioral parameters defining prey detection in A. stuartgranti $(n=6$ fish $)$ and 778 Tramitichromis ( $n=6$ fish) at five different light intensities. (a, c, e) Mean ( \pm s.e.m.) number of 779 prey detections (maximum 6 live, 6 dead tethered brine shrimp), detection distance, and 780 detection-to-strike velocity, for A. stuartgranti feeding on live ( $\rightarrow-)$ and dead ( --- ---$)$ prey, and 781 (b, d, f) Tramitichromis feeding on live (־-) and dead ( -.- - -.. ') prey 
783 Fig. 5 Frequency of prey strikes (live and dead prey combined, 12 total prey/trial) during glide or 784 pause phases of swimming at five different light intensities in $\mathbf{a}$ A. stuartgranti ( $n=6$ fish) and $\mathbf{b}$ 785 Tramitichromis $(n=6$ fish $)$

786

787 Fig. 6 Detection angle for live and dead prey combined (=12 total prey/trial) at five different 788 light intensities for $\mathbf{a}$ A. stuartgranti ( $n=6$ fish) and $\mathbf{b}$ Tramitichromis $(n=6$ fish). Black lines 789 represent the proportion of prey detections grouped into $20^{\circ}$ intervals. Fish snout is at the center 790 and fish is facing $0^{\circ}$ (indicated by the grey arrow in the top plot in a). The thin line represents the 791 mean angle for all trials. Results for Tramitichromis at 0 lx were not included here due to the 792 small number of strikes $(n=3$ strikes $)$

793

794 Fig. 7 Mean ( \pm s.e.m.) prey preference scores (following Taplin 2007) for a A. stuartgranti $(n=$ 7956 fish) and b Tramitichromis ( $n=6$ fish) feeding on six live (white bars) and six dead (gray bars) 796 tethered adult brine shrimp in trials at five different light intensities. Preferences scores were 797 calculated by taking the mean of the rank order in which prey were captured. The dotted line (= 798 6.5) indicates the mean preference score with no preference for either prey type. Scores $<6.5$ 799 (below dotted line) indicate a preference. Significantly different preference scores between live 800 and dead prey indicated by an asterisk (*, paired $t$-test, $P<0.05$, Table 5) 
Table 1 The relationship of measured light intensity (mean lux and PAR, \pm s.e.m. measured immediately after behavioral trials) and predicted depths at which these intensities occur in Lake Malawi. Calculations were based on midday sunlight levels, three light extinction coefficients $\left(0.10 \mathrm{~m}^{-1}\right.$, Patterson et al. 2000; $0.13 \mathrm{~m}^{-1}, 0.43 \mathrm{~m}^{-1}$, Guildford et al. 2007), and light intensities under natural conditions (Harden Jones 1955, Ali 1959). Light intensities were achieved by varying the height of two fluorescent fixtures (ballasts) and/or covering these fixtures with several neutral density filters

\begin{tabular}{llllll}
\hline Light Intensity & & \multicolumn{3}{l}{ Light Extinction Coefficient } & \\
Lux & PAR & $\varepsilon=0.10 \mathrm{~m}^{-1}$ & $\varepsilon=0.13 \mathrm{~m}^{-1}$ & $\varepsilon=0.43 \mathrm{~m}^{-1}$ & \\
Lumen $/ \mathrm{m}^{2}$ & $\mu \mathrm{mol}$ photons $/ \mathrm{m}^{2} / \mathrm{s}$ & Depth $(\mathrm{m})$ & Depth $(\mathrm{m})$ & Depth $(\mathrm{m})$ & Light intensities under natural conditions \\
\hline $800(800.8 \pm 5.4)$ & $11.0(11.0 \pm 0.10)$ & 52 & 40 & 12 & Very cloudy day \\
$112(112.4 \pm 1.9)$ & $1.5(1.51 \pm 0.03)$ & 72 & 55 & 17 & Twilight \\
$12(12.0 \pm 0.3)$ & $0.2(0.16 \pm 0.01)$ & 92 & 71 & 21 & Twilight \\
$1(1.4 \pm 0.1)$ & $0.03(0.03 \pm 0.01)$ & 115 & 89 & 27 & Full moon/deep twilight \\
$0(0 \pm 0.1)$ & $0(0.000 \pm 0.003)$ & $\mathrm{NA}$ & $\mathrm{NA}$ & $\mathrm{NA}$ & New moon \\
\hline
\end{tabular}


Table 2 Determination of GLMM types used to analyze four parameters of feeding behavior at five different light intensities $(0-800 \mathrm{~lx})$ in interspecific and intraspecific comparisons

\begin{tabular}{|c|c|c|c|c|}
\hline Source & Distribution & Link & $\begin{array}{l}\text { Covariance } \\
\text { Structure }\end{array}$ & AICC \\
\hline \multicolumn{5}{|l|}{ 4-way GLMMs } \\
\hline Number of prey strikes & Multinomial & Negative log-log & $\operatorname{AR}(1)$ & $1,713.0$ \\
\hline Detection distance & Normal* & Identity & $\operatorname{AR}(1)$ & 177.9 \\
\hline Detection-to-strike velocity & Normal* & Identity & $\operatorname{AR}(1)$ & -32.4 \\
\hline Swimming phase at prey detection & Binomial & Probit & $\operatorname{AR}(1)$ & 1932.8 \\
\hline \multicolumn{5}{|l|}{ 3-way GLMMs } \\
\hline \multicolumn{5}{|l|}{ Aulonocara stuartgranti } \\
\hline Number of prey strikes & Multinomial & Probit & $\operatorname{AR}(1)$ & 698.1 \\
\hline Detection distance & Normal* & Identity & $\mathrm{AR}(1)$ & 44.9 \\
\hline Detection-to-strike velocity & Normal* & Identity & $\operatorname{AR}(1)$ & -24.6 \\
\hline Swimming phase at prey detection & Binomial & Probit & $\mathrm{AR}(1)$ & 1065.9 \\
\hline \multicolumn{5}{|l|}{ Tramitichromis } \\
\hline Number of prey strikes & Multinomial & Negative log-log & $\mathrm{AR}(1)$ & 955.4 \\
\hline Detection distance & Normal* & Identity & $\mathrm{AR}(1)$ & 130.6 \\
\hline Detection-to-strike velocity & Normal* & Identity & $\mathrm{AR}(1)$ & -7.2 \\
\hline Swimming phase at prey detection & Binomial & Probit & $\operatorname{AR}(1)$ & 869.1 \\
\hline
\end{tabular}

Note: the table includes information on the error distribution and link function. The first-order auto-regressive process $[\mathrm{AR}(1)]$ was used for the covariance structure in all models. The most parsimonious model was selected based on the corrected Akaike information criterion (AICC).

*Data was $\log 10$ transformed to achieve normality (normality assessed with Kolmogorov-Smirnov test). 
Table 3 Summary of 4-way GLMM statistics for prey detection behavior for two species (A. stuartgranti, $n=6$ fish; Tramitichromis, $n=6$ fish) feeding on two prey types (live, dead) at five light intensities (0-800 lx). Only those factors that are significant for at least one behavioral parameter are listed. See Table 2 for details of GLMMs used

\begin{tabular}{|c|c|c|c|c|c|c|c|c|}
\hline \multirow[b]{3}{*}{ Source } & \multicolumn{4}{|c|}{ Number of prey } & \multicolumn{2}{|c|}{ Detection-to-strike } & \multicolumn{2}{|c|}{ Swimming phase at prey } \\
\hline & detections & & & & velocity & & detection & \\
\hline & $F(d f)$ & $P$ value & $F(d f)$ & $P$ value & $F(d f)$ & $P$ value & $F(d f)$ & $P$ value \\
\hline Species (S) & & n.s. & & n.s. & & n.s. & & n.s. \\
\hline Light intensity (L) & $14.390(1,99)$ & $<0.001$ & $9.480(1,481)$ & 0.002 & $8.919(1,511)$ & 0.003 & $8.276(1,18)$ & $\mathbf{0 . 0 1 0}$ \\
\hline Time of day $(\mathrm{T})$ & $22.203(1,99)$ & $<0.001$ & $17.342(1,512)$ & $<0.001$ & $16.838(1,513)$ & $<0.001$ & $0.038(1,129)$ & 0.847 \\
\hline Prey type $(\mathrm{P})$ & $4.549(1,99)$ & 0.035 & $1.145(1,503)$ & 0.285 & $3.876(1,504)$ & 0.050 & $3.037(1,514)$ & 0.082 \\
\hline $\mathrm{S} \times \mathrm{L}$ & $8.950(1,99)$ & 0.004 & & n.s. & & n.s. & & n.s. \\
\hline $\mathrm{S} \times \mathrm{P}$ & & n.s. & & n.s. & & n.s. & $4.288(1,514)$ & 0.039 \\
\hline $\mathrm{L} \times \mathrm{T}$ & $14.101(1,99)$ & $<0.001$ & $10.479(1,482)$ & 0.001 & $9.957(1,512)$ & 0.002 & $6.044(1,62)$ & 0.017 \\
\hline $\mathrm{S} \times \mathrm{L} \times \mathrm{T}$ & $10.464(1,99)$ & 0.002 & & n.s. & & n.s. & & n.s. \\
\hline
\end{tabular}

n.s. $=$ not significant $(P>0.05)$

$P$ values $<0.05$ are shown in bold 
Table 4 Summary of 3-way GLMM statistics for prey detection behavior for $A$. stuartgranti $(n=$ 6 fish) and Tramitichromis ( $n=6$ fish) feeding on two prey types (live, dead) at five different light intensities (0-800 1x). See Table 2 for details of GLMMs used

\begin{tabular}{lllll}
\hline & \multicolumn{2}{l}{ Aulonocara stuartgranti } & Tramitichromis \\
Model term & $F(d f)$ & $P$ value & $F(d f)$ & $P$ value \\
\hline Number of prey detections & & & \\
Light intensity (L) & $0.282(1,47)$ & 0.598 & $11.867(1,47)$ & $\mathbf{0 . 0 0 1}$ \\
Time of day (T) & $11.212(1,47)$ & $\mathbf{0 . 0 0 2}$ & $23.887(1,47)$ & $<\mathbf{0 . 0 0 1}$ \\
Prey type (P) & $1.649(1,47)$ & 0.205 & $0.109(1,47)$ & 0.743 \\
L $\times \mathrm{T}$ & $0.293(1,47)$ & 0.591 & $12.162(1,47)$ & $\mathbf{0 . 0 0 1}$ \\
$\mathrm{L} \times \mathrm{P}$ & $0.845(1,47)$ & 0.363 & $0.078(1,47)$ & 0.780 \\
$\mathrm{~T} \times \mathrm{P}$ & $0.968(1,47)$ & 0.330 & $0.003(1,47)$ & 0.956 \\
$\mathrm{~L} \times \mathrm{T} \times \mathrm{P}$ & $0.675(1,47)$ & 0.416 & $0.037(1,47)$ & 0.847
\end{tabular}

Detection distance

$\begin{array}{lllll}\text { Light intensity (L) } & 2.772(1,242) & 0.097 & 6.185(1,217) & \mathbf{0 . 0 1 4} \\ \text { Time of day (T) } & 26.812(1,291) & <\mathbf{0 . 0 0 1} & 5.655(1,223) & \mathbf{0 . 0 1 8} \\ \text { Prey type (P) } & 8.220(1,286) & \mathbf{0 . 0 0 4} & 0.000(1,217) & 0.986 \\ \mathrm{~L} \times \mathrm{T} & 3.408(1,240) & 0.066 & 6.677(1,217) & \mathbf{0 . 0 1 0} \\ \mathrm{L} \times \mathrm{P} & 0.002(1,286) & 0.965 & 4.019(1,220) & \mathbf{0 . 0 4 6} \\ \mathrm{T} \times \mathrm{P} & 4.604(1,286) & \mathbf{0 . 0 3 3} & 0.026(1,217) & 0.872 \\ \mathrm{~L} \times \mathrm{T} \times \mathrm{P} & 0.004(1,286) & 0.949 & 4.211(1,220) & \mathbf{0 . 0 4 1}\end{array}$

Detection-to-strike velocity

$\begin{array}{lcccc}\text { Light intensity (L) } & 3.158(1,200) & 0.077 & 4.695(1,223) & \mathbf{0 . 0 3 1} \\ \text { Time of day (T) } & 16.895(1,290) & <\mathbf{0 . 0 0 1} & 8.058(1,221) & \mathbf{0 . 0 0 5} \\ \text { Prey type (P) } & 20.107(1,286) & <\mathbf{0 . 0 0 1} & 0.012(1,218) & 0.912 \\ \text { L } \times \text { T } & 3.465(1,198) & 0.064 & 5.495(1,223) & \mathbf{0 . 0 2 0}\end{array}$




$\begin{array}{lllll}\mathrm{L} \times \mathrm{P} & 0.385(1,286) & 0.535 & 2.220(1,219) & 0.138 \\ \mathrm{~T} \times \mathrm{P} & 14.330(1,286) & <\mathbf{0 . 0 0 7} & 0.014(1,218) & 0.907 \\ \mathrm{~L} \times \mathrm{T} \times \mathrm{P} & 0.393(1,286) & 0.531 & 2.300(1,219) & 0.131\end{array}$

Swimming phase at prey detection

\begin{tabular}{lllll} 
Light intensity (L) & $0.289(1,291)$ & 0.592 & $3.208(1,223)$ & 0.075 \\
Time of day (T) & $1.593(1,291)$ & 0.208 & $0.068(1,223)$ & 0.794 \\
Prey type (P) & $0.147(1,291)$ & 0.701 & $3.794(1,223)$ & 0.053 \\
$\mathrm{~L} \times \mathrm{T}$ & $0.128(1,291)$ & 0.720 & $2.873(1,223)$ & 0.091 \\
$\mathrm{~L} \times \mathrm{P}$ & $0.220(1,291)$ & 0.639 & $0.433(1,223)$ & 0.511 \\
$\mathrm{~T} \times \mathrm{P}$ & $0.202(1,291)$ & 0.653 & $2.588(1,223)$ & 0.109 \\
$\mathrm{~L} \times \mathrm{T} \times \mathrm{P}$ & $0.211(1,291)$ & 0.646 & $0.438(1,223)$ & 0.509 \\
\hline
\end{tabular}

$P$ values $<0.05$ are shown in bold 
Table 5 Summary of the paired $t$-tests comparing prey preference scores of live versus dead prey of A. stuartgranti and Tramitichromis (following Taplin 2007) by light intensity

\begin{tabular}{lll}
\hline Light intensity $(\mathrm{lx})$ & $T(d f)$ & $P$ value \\
\hline Aulonocara stuartgranti & & \\
0 & $-2.853(5)$ & $\mathbf{0 . 0 3 6}$ \\
1 & $-0.618(5)$ & 0.564 \\
12 & $-1.395(5)$ & 0.222 \\
112 & $-6.102(5)$ & $\mathbf{0 . 0 0 2}$ \\
800 & $-1.892(5)$ & 0.117 \\
Tramitichromis & $-0.797(5)$ & 0.461 \\
0 & $-2.396(5)$ & 0.062 \\
1 & $-1.379(5)$ & 0.226 \\
12 & $-2.441(5)$ & 0.059 \\
112 & $-13.647(5)$ & $<\mathbf{0 . 0 0 1}$ \\
\hline & & \\
\hline
\end{tabular}

$P$ values $<0.05$ are shown in bold 

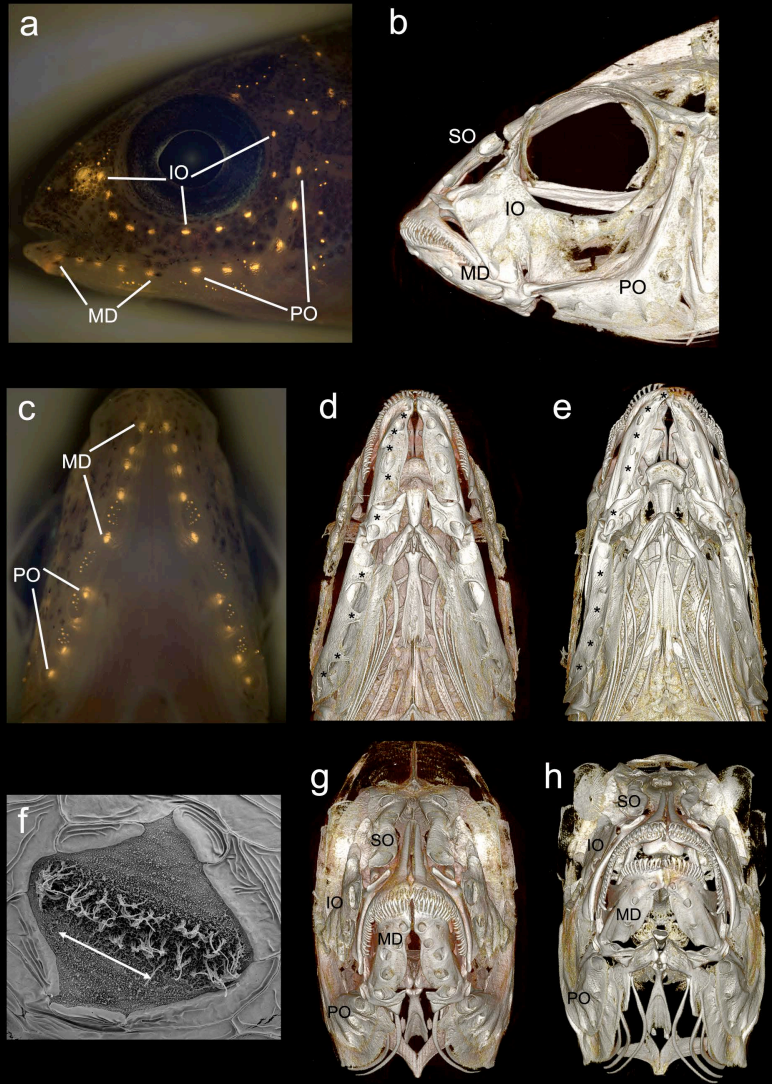

hค.
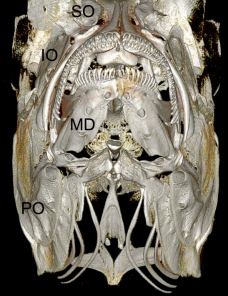


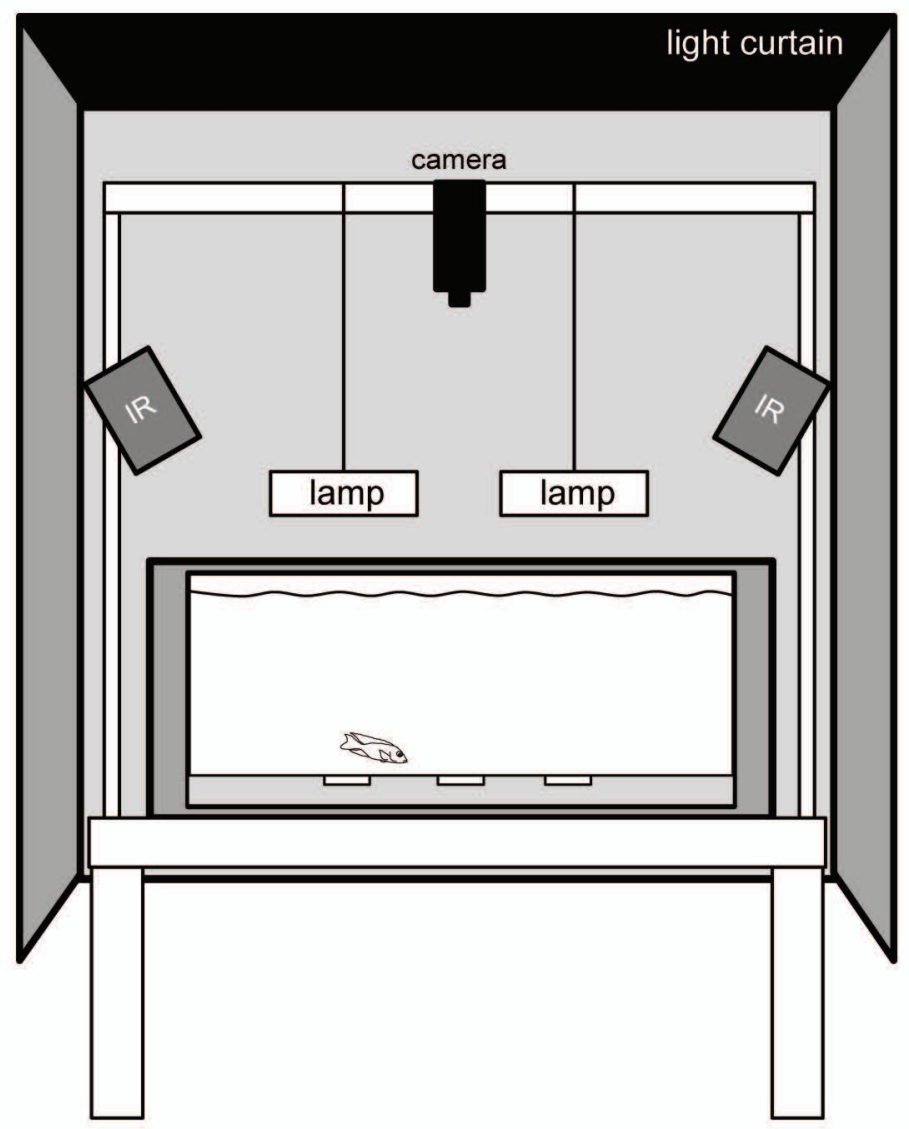

b
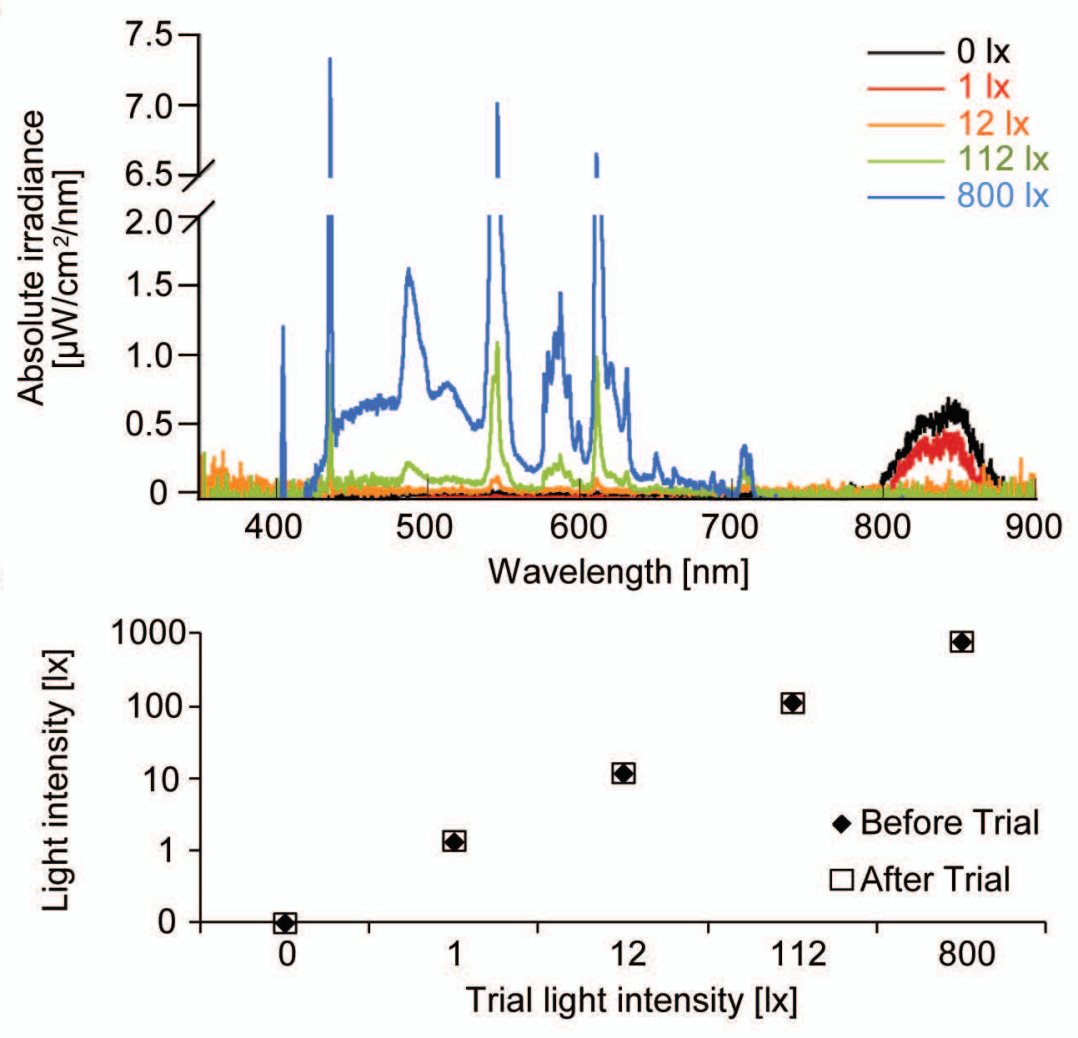
Aulonocara stuartgranti

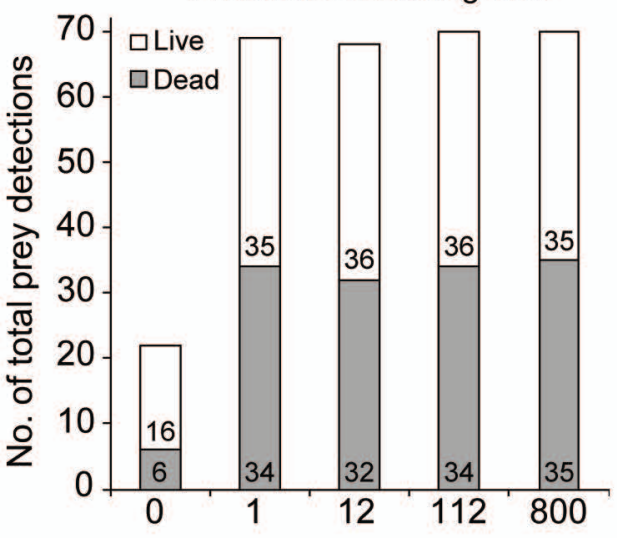

Light intensity [lx] b Tramitichromis

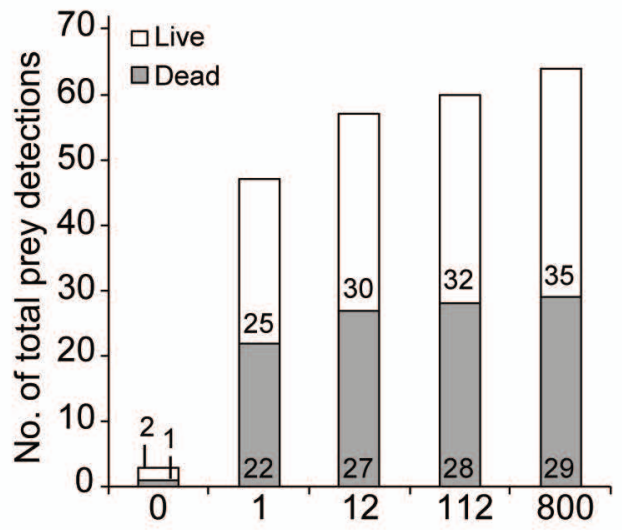

Light intensity [lx] 
a
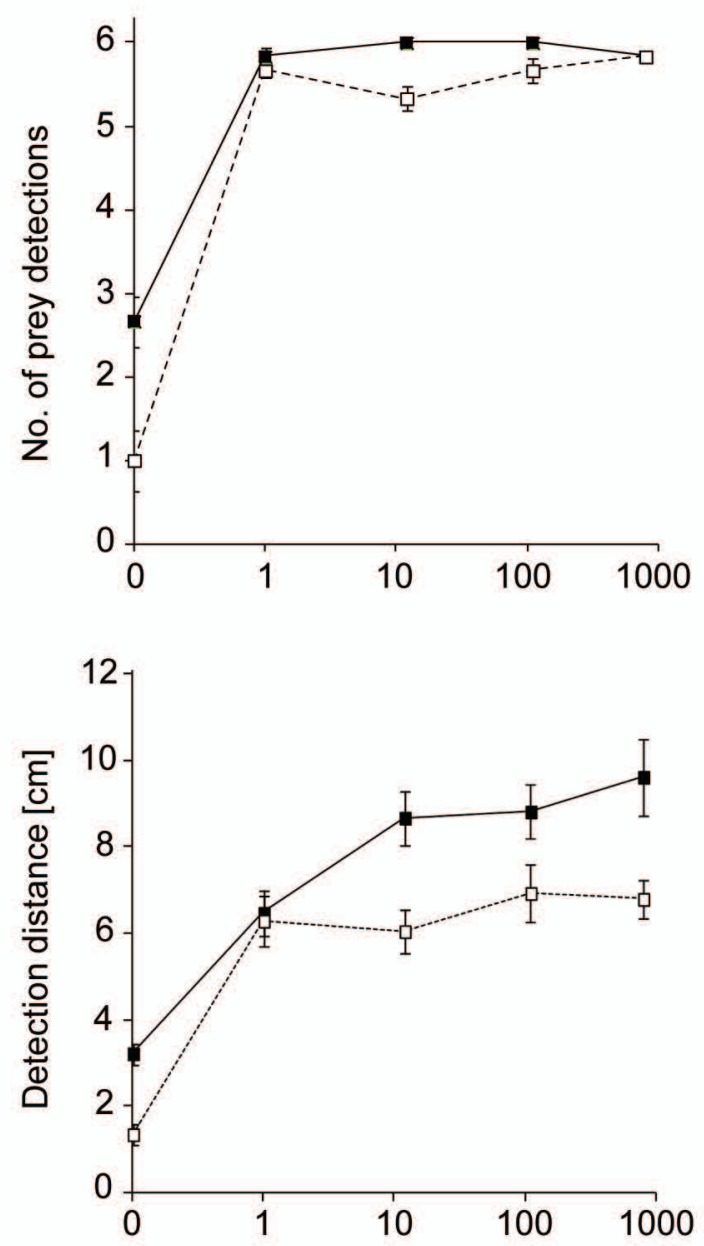

e

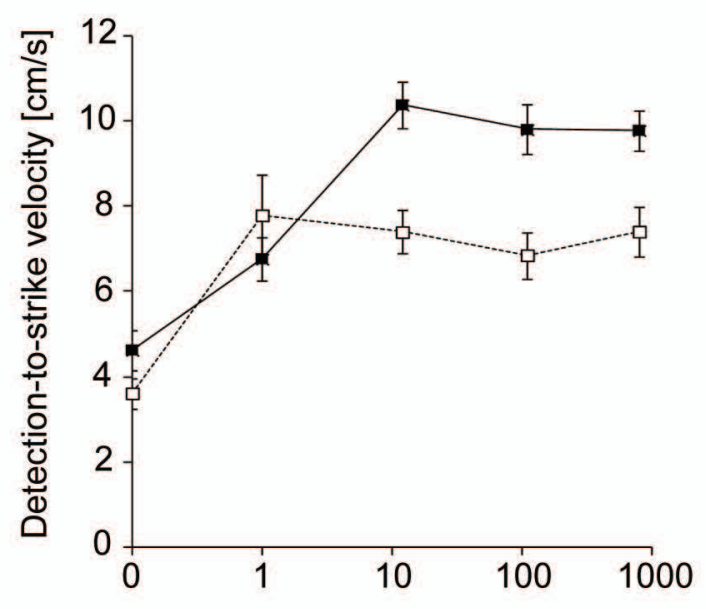

Light intensity [Ix]

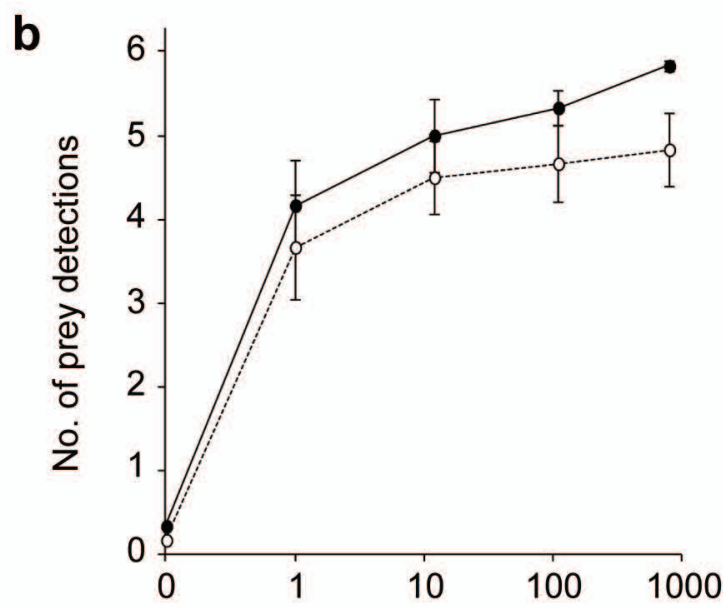

d
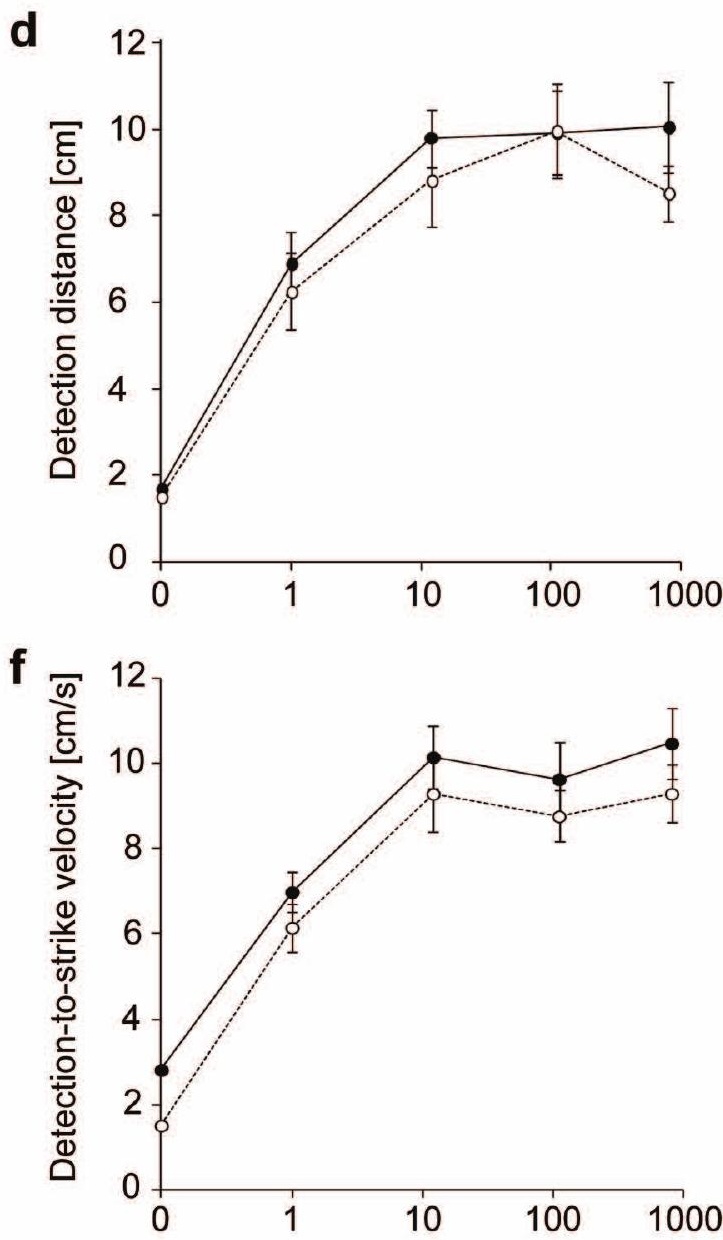

Light intensity [Ix] 

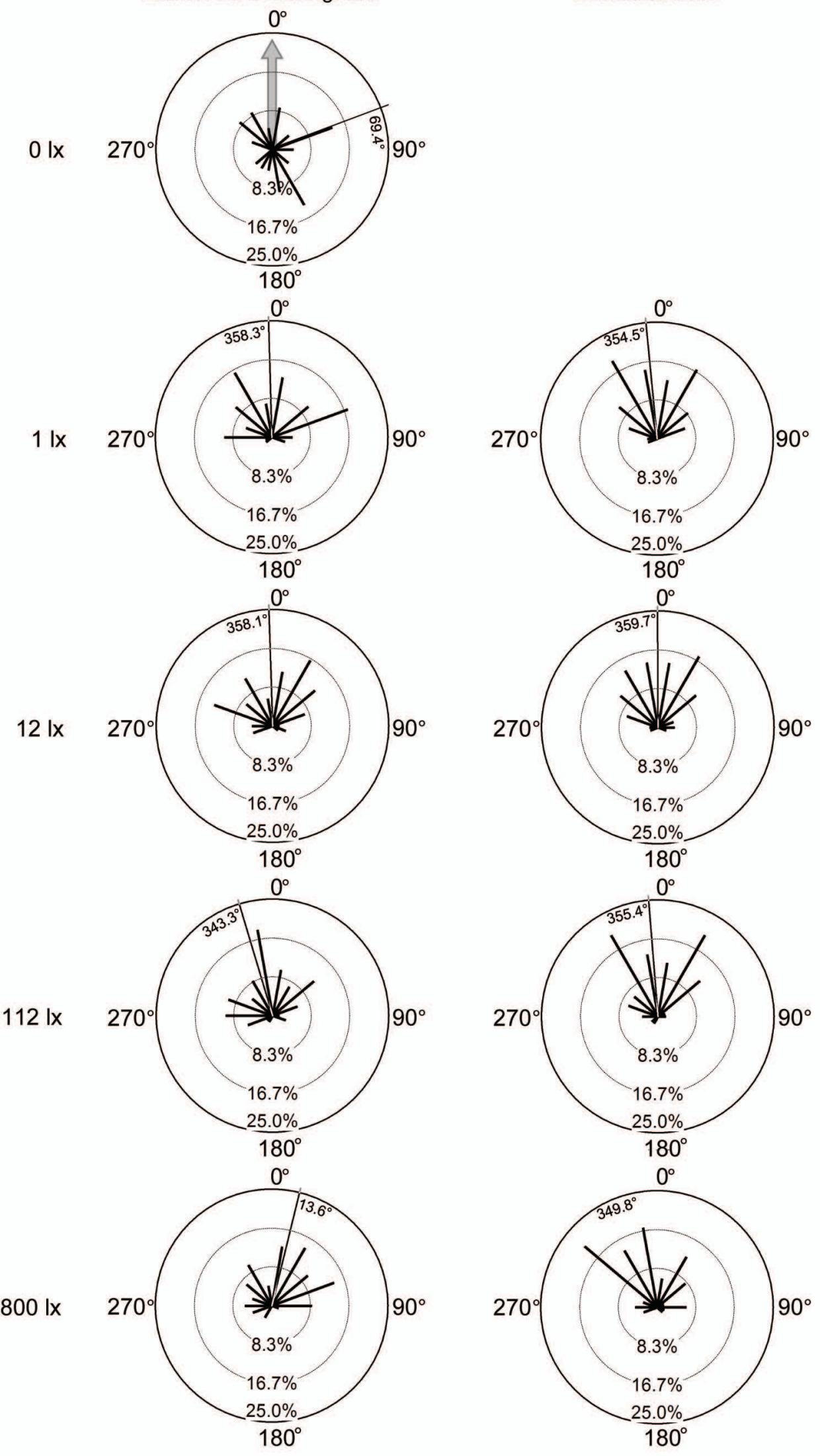


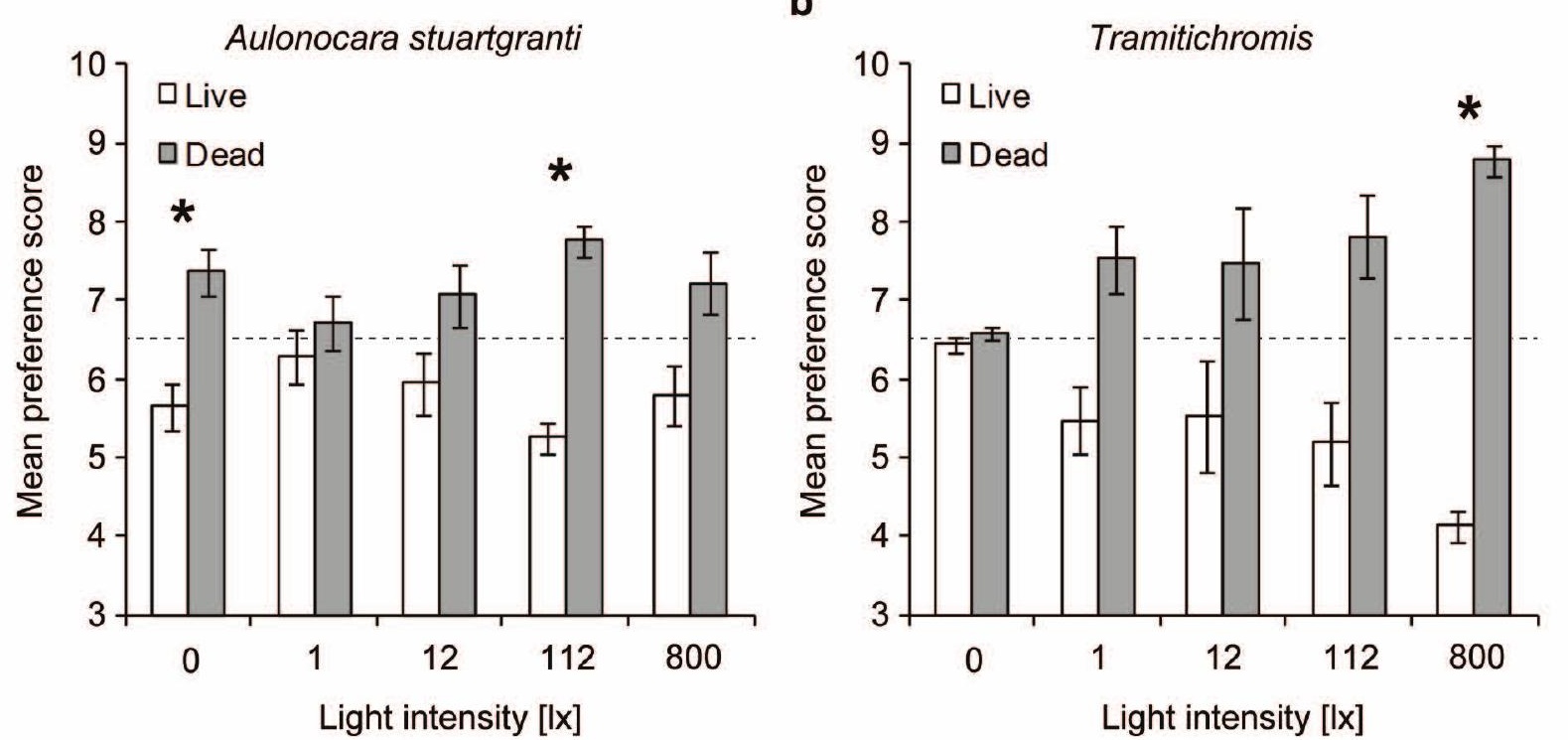

